\title{
Modelling the transition from grain-boundary sliding to power-law creep in dry snow densification
}

\section{Article}

Cite this article: Morris EM, Montgomery LN, Mulvaney R (2022). Modelling the transition from grain-boundary sliding to power-law creep in dry snow densification. Journal of Glaciology 68(269), 417-430. https://doi.org/ 10.1017/jog.2021.95

Received: 20 March 2021

Revised: 22 July 2021

Accepted: 2 August 2021

First published online: 8 September 2021

Key words:

Ice core; polar firn; snow physics

Author for correspondence:

Elizabeth M. Morris,

E-mail:emm36@cam.ac.uk

\section{Elizabeth M. Morris ${ }^{1}$ (D), Lynn N. Montgomery ${ }^{2}$ (D) and Robert Mulvaney ${ }^{3}$ (D)}

${ }^{1}$ Scott Polar Research Institute, Lensfield Road, Cambridge CB2 1ER, UK; ${ }^{2}$ Department of Atmospheric and Oceanic Science, University of Colorado, Boulder, CO, USA and ${ }^{3}$ British Antarctic Survey, High Cross, Madingley Road, Cambridge CB3 OET, UK

\section{Abstract}

This paper presents a physics-based macroscale model for the densification of dry snow which provides for a smooth transition between densification by grain-boundary sliding (stage 1) and densification by power-law creep (stage 2). The model uses established values of the stage 1 and 2 densification rates away from the transition zone and two transition parameters with a simple physical basis: the transition density and the half-width of the transition zone. It has been calibrated using density profiles from the SUMup database and physically based expressions for the transition parameters have been derived. The transition model produces better predictions of the depth of the nominal bubble close-off horizon than the Herron and Langway model, both in its classical form and in a recent version with re-optimised densification rates.

\section{List of symbols}

DIP depth-integrated porosity, $\mathrm{m}$

$E_{0} \quad$ stage 1 activation energy, $\mathrm{kJ} \mathrm{mol}^{-1}$

$E_{1} \quad$ stage 2 activation energy, $\mathrm{kJ} \mathrm{mol}^{-1}$

$H \quad$ depth of ice sheet, $\mathrm{m}$

$N$ number of measurements

$R \quad$ logarithmic function of density

$R_{\mathrm{s}} \quad$ polynomial curve fitted to $R$

$R_{\text {model }}$ model values of $R$

$R_{\text {obs }} \quad$ observed values of $R$

$T_{\mathrm{m}} \quad$ mean annual firn temperature, ${ }^{\circ} \mathrm{C}$ or $\mathrm{K}$

$X \quad$ scaled density variable, $\mathrm{a}^{-1}$

$X_{0} \quad$ surface value of $X, \mathrm{a}^{-1}$

$\bar{a} \quad$ mean annual accumulation rate, $\mathrm{m}$ w.e. $\mathrm{a}^{-1}$

$c$ density-corrected volumetric strain rate, $\mathrm{a}^{-1}$

$k_{0} \quad$ local stage 1 densification rate, $\mathrm{m}$ w.e. ${ }^{-1}$

$k_{0}^{*} \quad$ global stage 1 densification rate, $\mathrm{m}$ w.e. ${ }^{-1}$

$k_{1} \quad$ local stage 2 densification rate, $\mathrm{m}$ w.e. ${ }^{-1}$

$k_{1}^{*} \quad$ global stage 2 densification rate, $\mathrm{m}$ w.e. ${ }^{-1}$

$q_{\mathrm{T}} \quad$ water-equivalent depth at transition, $\mathrm{m}$ w.e.

$z \quad$ height, $\mathrm{m}$

$z_{\mathrm{T}} \quad$ transition height, $\mathrm{m}$

$z_{\mathrm{s}} \quad$ smoothed profile height, $\mathrm{m}$

$z_{\mathrm{BCO}} \quad$ bubble close off height, $\mathrm{m}$

$z_{\text {model }}$ model height, $\mathrm{m}$

A parameter in transition model, $\mathrm{a}^{2}$

parameter in transition model, $\mathrm{a}^{-1}$

parameter in transition model, $\mathrm{a}^{-1}$ parameter in transition model, $\mathrm{a}^{-1}$

parameter in transition model, $\mathrm{kg}^{2} \mathrm{~m}^{-6} \mathrm{a}^{2}$ gas constant, $8.314 \mathrm{~J} \mathrm{~mol}^{-1} \mathrm{~K}^{-1}$

$\triangle D I P \quad$ difference in depth-integrated porosity, $\mathrm{m}$

(c) The Author(s), 2021. Published by Cambridge University Press. This is an Open Access article, distributed under the terms of the Creative Commons Attribution licence (http://creativecommons.org/licenses/by/4.0/), which permits unrestricted re-use, distribution, and reproduction in any medium, provided the original work is properly cited. difference in BCO height, $\mathrm{m}$

transition half-width, $\mathrm{kg} \mathrm{m}^{-3}$

thinning function

cost function

minimum value of cost function

parameter in Herron and Langway equation parameter in Herron and Langway equation

volumetric strain rate, $\mathrm{a}^{-1}$

horizontal flow divergence, $\mathrm{a}^{-1}$

vertical strain rate, $\mathrm{a}^{-1}$ 
$\lambda \quad$ length scale, $\mathrm{m}$

$\rho \quad$ mean density over a macroscale element, $\mathrm{kg} \mathrm{m}^{-3}$

$\rho^{\prime} \quad$ variable density within a macroscale element, $\mathrm{kg} \mathrm{m}^{-3}$

$\rho_{0} \quad$ surface intercept density, $\mathrm{kg} \mathrm{m}^{-3}$

$\rho_{1} \quad$ lowest density in optimisation range, $\mathrm{kg} \mathrm{m}^{-3}$

$\rho_{2} \quad$ highest density in optimisation range, $\mathrm{kg} \mathrm{m}^{-3}$

$\rho_{\mathrm{T}} \quad$ transition density, $\mathrm{kg} \mathrm{m}^{-3}$

$\rho_{\mathrm{T}}^{\prime} \quad$ variable transition density within a macroscale element, $\mathrm{kg} \mathrm{m}^{-3}$

$\rho_{\mathrm{i}} \quad$ density of ice, $\mathrm{kg} \mathrm{m}^{-3}$

$\rho_{\mathrm{w}} \quad$ density of water, $\mathrm{kg} \mathrm{m}^{-3}$

$\rho_{\mathrm{BCO}} \quad$ nominal bubble close off density, $\mathrm{kg} \mathrm{m}^{-3}$

$\sigma \quad$ overburden stress, $\mathrm{Pa}$

$\tau \quad$ time from deposition, a

$\tau_{\mathrm{T}} \quad$ time from deposition to transition, a

$\theta_{\mathrm{BCO}}$ thinning correction at bubble close off, $\mathrm{m}$

$\varepsilon_{\mathrm{T}} \quad$ total strain to transition

\section{Introduction}

Models of the densification of dry snow are used for a wide range of glaciological and meteorological purposes, including, for example, predicting the energy budget at the lower boundary of the atmosphere in climate models, predicting the formation of weak layers in avalanche models, interpretation of seismic and radar-sounding data and derivation of age-depth relations for firn cores. In particular, two key problems are often identified as drivers for the development of firn densification models. The first concerns the interpretation of altimetry data, in particular the satellite data which have revealed the response of the polar ice sheets to recent climate change. A change in elevation of an element of the ice-sheet surface can occur both because of a change in the mass of the underlying ice and firn column and because of a change in its depth-integrated porosity (DIP). A model is needed to predict how DIP will vary with changing climate before elevation changes can be linked to mass-balance changes. The second problem concerns the interpretation of ice core palaeoclimate and atmosphere data. The age of gas bubbles in an ice core segment will not be the same as the age of the surrounding ice because the gas is able to move while in the porous firn region. Estimating the age difference, so that climate variables deduced from the gas and ice chemistry can be reconciled, requires a densification model to predict bubble close-off (BCO) depth in the firn.

Snow densification models range from the relatively simple linear viscous approximations used in seasonal snow cover models (e.g. Brun and others, 1989; Jordan, 1991; Bader and Weilenmann, 1992) to more complex formulations based on details of physical processes at the grain-size scale (e.g. Salamatin and others, 2009; Fourteau and others, 2020). In many applications the input data are limited, and this in turn limits the complexity of the models that can be used. One widely used model developed by Herron and Langway (1980) defines densification rates at a given site simply in terms of the mean annual firn temperature, $T_{\mathrm{m}}$, mean annual accumulation, $\bar{a}$, and surface intercept density, $\rho_{0}$. This may be regarded as the 'common ancestor' (Lundin and others, 2017) of a number of other macroscale models that rely on similar input data and share common assumptions about the densification process.

One of these assumptions is that snow densification occurs first by rearrangement of the ice grains to produce a closer packing. The grains move by sliding at their boundaries until the closest possible packing is achieved, at which point further densification is only possible by plastic deformation of the grains themselves. This power-law creep continues until the pores in the matrix are enclosed and further densification then depends on compression of the gas in the bubbles. The Herron and
Langway (1980) model defines a fixed transition density for all sites, $\rho_{\mathrm{T}}$, between the first and second stages of densification, as $550 \mathrm{~kg} \mathrm{~m}^{-3}$. This value is physically plausible, since it lies between the densities of the loosest $\left(479 \mathrm{~kg} \mathrm{~m}^{-3}\right)$ and closest $\left(679 \mathrm{~kg} \mathrm{~m}^{-3}\right)$ theoretical packing of ice spheres (Benson, 1962), and has continued to be used in current models (e.g. Barnola and others, 1991; Spencer and others, 2001; Goujon and others, 2003; Arthern and others, 2010; Ligtenberg and others, 2011; Simonsen and others, 2013; Verjans and others, 2020).

Nevertheless, the possibility that $\rho_{\mathrm{T}}$ is not a constant was raised early in the development of densification models. On the somewhat uncertain basis of four density profiles, Benson (1962) derived an empirical expression in terms of $T_{\mathrm{m}}$ which implies a maximum value of $730 \mathrm{~kg} \mathrm{~m}^{-3}$ at $0^{\circ} \mathrm{C}$ and a minimum value of $500 \mathrm{~kg} \mathrm{~m}^{-3}$, no matter how cold the snow becomes. He suggested near-zero temperatures favour stage 1 densification because the formation of a liquid layer at the grain-boundaries allows this stage to continue to a greater density. Arnaud and others (1998) agreed that the transition density decreases with temperature; their explanation was that the overburden stress, $\sigma$, at the transition is greater at cold sites, so that densification by creep $\left(\alpha \sigma^{3}\right)$ is favoured over densification by grain-boundary sliding $(\propto \sigma)$ and can begin at a lower density.

The idea that stages 1 and 2 are separated by an abrupt transition was challenged early on by Ebinuma and Maeno (1987) who suggested that particle rearrangement and plastic creep can operate together over a wide transition region from $550 \mathrm{~kg} \mathrm{~m}^{-3}$ to $\sim 700 \mathrm{~kg} \mathrm{~m}^{-3}$. These densities were deduced from ice core data at relatively low resolution (spacing $\geq 50 \mathrm{~cm}$ ). Higher resolution profiles reveal the variation in density between and within annual layers and have led to a more detailed understanding of the physical processes controlling densification in dry polar snow. In particular, Gerland and others (1999) and Freitag and others (2004) showed that initially lower-density, coarse grained, 'summer firn' layers had a higher stage 1 densification rate than initially higher-density, fine-grained 'winter firn' and Hörhold and others (2012) showed that a variation in impurity concentration could produce a variation in stage 2 densification rates. This variability in both density and densification rates will broaden the range over which the transition from stages 1 to 2 appears to occur on the macroscale, that is when we consider the smoothed density profile rather than details of the annual layering.

The concept of a transition zone was incorporated into the Herron and Langway model by Morris (2018). The 'Morris transition model' removes the abrupt transition between stage 1 and stage 2 densification at a fixed transition density and includes two optimisable parameters. These are the transition density, $\rho_{\mathrm{T}}$, and the transition half-width, $\Delta \rho$, a measure of the density range over which the transition occurs. Early values of these parameters were determined by examination of short strain rate profiles from the Pine Island Glacier basin, Antarctica (Morris and others, 2017). This paper extends that work using 103 profiles from the SUMup community dataset of snow and firn density (Montgomery and others, 2018). We develop new, physically based, expressions for the transition parameters and assess the performance of the model in terms of its ability to predict the nominal BCO depth for 45 of the profiles.

\section{The transition model}

The transition model is based on the Robin hypothesis that, in dry snow, the volumetric strain rate, $\dot{\varepsilon}$, is related to the (macroscale) density $\rho$ by the expression

$$
\dot{\varepsilon}=c\left(\frac{\rho_{\mathrm{i}}-\rho}{\rho}\right),
$$


where $\rho_{\mathrm{i}}$ is the density of ice. The density-corrected volumetric strain rate, $c$, is written

$$
c=\left(\mathrm{D}+\frac{X}{\left|\left(1+\mathrm{A} X^{2}\right)^{1 / 2}\right|}\right)
$$

where A and D are constants and $X=\left(\rho-\rho_{\mathrm{T}}\right) / \mathrm{M}^{1 / 2}$ is a scaled density variable describing distance from the transition density $\rho_{\mathrm{T}}$. Away from the transition $c$ tends to the stage 1 and stage 2 constant density-corrected strain rates. That is, for $A X^{2} \gg 1$, $c \rightarrow\left(D-A^{-1 / 2}\right)$ or $\left(D+A^{-1 / 2}\right)$. Parameter $M$ controls the abruptness of the transition. The half-width of the transition, $\Delta \rho$, is defined by the points where $c$ reaches $90 \%$ of its stage 1 and stage 2 values, that is

$$
\begin{array}{ll}
\rho=\rho_{\mathrm{T}}-\Delta \rho & \text { for } \quad c=0.9\left(\mathrm{D}-\mathrm{A}^{-1 / 2}\right), \\
\rho=\rho_{\mathrm{T}}+\Delta \rho & \text { for } \quad c=0.9\left(\mathrm{D}+\mathrm{A}^{-1 / 2}\right),
\end{array}
$$

from which

$$
\Delta \rho \approx 2.06\left(\frac{\mathrm{M}}{A}\right)^{1 / 2}
$$

For constant $\bar{a}$, we can derive an expression relating height, $z$, (positive upwards) and scaled density $X$ :

$$
\begin{aligned}
\int \mathrm{d} z= & \frac{\bar{a}}{\mathrm{M}^{1 / 2}} \\
& \times \int \frac{\left(1+\mathrm{A} X^{2}\right)^{1 / 2} \mathrm{~d} X}{\left(\mathrm{D}\left(1+\mathrm{A} X^{2}\right)^{1 / 2}+X\right)(\mathrm{C}-X)(X-\mathrm{B})},
\end{aligned}
$$

where $\mathrm{B}=-\rho_{\mathrm{T}} / \mathrm{M}^{1 / 2}$ and $\mathrm{C}=\left(\rho_{\mathrm{i}}-\rho_{\mathrm{T}}\right) / \mathrm{M}^{1 / 2}$. Equation (5) allows us to calculate the depth at which any given density is reached, for example the nominal $\mathrm{BCO}$ depth, $-z_{\mathrm{BCO}}$, at which $\rho=$ $\rho_{\mathrm{BCO}}$. There is evidence (Martinerie and others, 1994) that the (macroscale) BCO density varies with climate, in particular increasing from $\approx 815 \mathrm{~kg} \mathrm{~m}^{-3}$ at $-15^{\circ} \mathrm{C}$ to $\approx 834 \mathrm{~kg} \mathrm{~m}^{-3}$ at $55^{\circ} \mathrm{C}$. In this paper, we set a nominal value $\rho_{\mathrm{BCO}}=815 \mathrm{~kg} \mathrm{~m}^{-3}$, following the example of the FirnMICE intercomparison of densification models (Lundin and others, 2017).

The model also leads to an analytic solution for the depth-integrated porosity

$$
\begin{aligned}
D I P & =\int_{z}^{0} \frac{\left(\rho_{\mathrm{i}}-\rho\right)}{\rho_{\mathrm{i}}} \mathrm{d} z \\
& =\frac{\bar{a}}{\rho_{\mathrm{i}}} \int_{X}^{X_{0}} \frac{\left(1+\mathrm{A} X^{2}\right)^{1 / 2} \mathrm{~d} X}{\left(\mathrm{D}\left(1+\mathrm{A} X^{2}\right)^{1 / 2}+X\right)(X-\mathrm{B})},
\end{aligned}
$$

where $X_{0}$ is the surface value of $X$. The water-equivalent depth at $\mathrm{BCO}$ is simply $\rho_{\mathrm{i}}\left(-z_{\mathrm{BCO}}-D I P_{\mathrm{BCO}}\right)$ and hence the $\mathrm{BCO}$ age may be calculated using the mean annual accumulation and Eqns (5) and (6). Analytical solutions for the integrals in these equations are given in Morris (2018).

As it stands the model has four parameters, all of which could be tuned to obtain the best fit to strain rate or density profiles. In order to pin down the effect of adding the two transition parameters, we choose to fix $\mathrm{D}$ and $\mathrm{A}$ so that $\left(\mathrm{D}-\mathrm{A}^{-1 / 2}\right)=-\bar{a} k_{0}$ and $\left(\mathrm{D}+\mathrm{A}^{-1 / 2}\right)=-\bar{a} k_{1}$ where $k_{0}$ and $k_{1}$ are the local stage 1 and stage 2 densification rates defined by Herron and Langway (1980). They are related to global rates $k_{0}^{*}$ and $k_{1}^{*}$ by Arrhenius expressions

$$
k_{0}=k_{0}^{*} \bar{a}^{(\alpha-1)} \exp \left(\frac{-E_{0}}{\mathrm{R} T_{\mathrm{m}}}\right)
$$

and

$$
k_{1}=k_{1}^{*} \bar{a}^{(\beta-1)} \exp \left(\frac{-E_{1}}{\mathrm{R} T_{\mathrm{m}}}\right)
$$

Here, $\mathrm{R}=8.314 \mathrm{~J} \mathrm{~mol}^{-1} \mathrm{~K}^{-1}$ is the gas constant, $T_{\mathrm{m}}$ is in degrees Kelvin and the stage 1 and 2 activation energies are $E_{0}=10.16$ $\mathrm{kJ} \mathrm{mol}^{-1}$ and $E_{1}=21.40 \mathrm{~kJ} \mathrm{~mol}^{-1}$ respectively. Herron and Langway (1980) set $\alpha=1$ and $\beta=0.5$ so that only $k_{1}$ is dependent on $\bar{a}$. In this case, the global vertical densification rates for stages 1 and 2 are $k_{0}^{*}=11 \mathrm{~m}$ w.e. ${ }^{-1}$ and $k_{1}^{*}=575 \mathrm{~m}^{\text {w.e. }}{ }^{-1 / 2} \mathrm{a}^{-1 / 2}$ respectively. Note that, for very low accumulation, these values can lead to the unrealistic situation of $k_{1}>k_{0}$.

This classical Herron and Langway model, which we shall refer to as the HL model, may be regarded as a benchmark model for dry snow densification (Lundin and others, 2017). Other researchers have since adapted the expressions for the densification rates; in particular, Verjans and others (2020) have derived an optimal set of the six parameters in Eqns (7) and (8) by minimising the difference between observed and predicted values of the variable $\left[D I P\left(\rho=830 \mathrm{~kg} \mathrm{~m}^{-3}\right)-D I P(z=-15 \mathrm{~m})\right]$ for a subset of the SUMup density profiles taken as a whole. The Verjans version of the Herron and Langway model, HL(V), can be taken as an example of the improvement that can be made by adjusting the densification rates while retaining an abrupt transition. However, we note that the $\mathrm{HL}(\mathrm{V})$ parameters were obtained using climate forcing from a regional climate model, rather than mean annual values $T_{\mathrm{m}}$ and $\bar{a}$.

By fixing $k_{0}$ and $k_{1}$ at the HL values, we can compare the improvement in model predictions produced by inclusion of a transition zone with that produced by optimisation of the densification rates. In this paper, we shall refer to this version of the transition model as HL(T). A similar exercise could, of course, be undertaken for other models with an abrupt transition.

In Morris (2018) the transition parameters of $\mathrm{HL}(\mathrm{T})$ were optimised to obtain the best fit to measured strain rate profiles using Eqns (1) and (2). However, few such strain rate data are available. Density profile data, on the other hand, are available for a wide range of climatic conditions. We therefore optimise $\rho_{\mathrm{T}}$ and $\Delta \rho$ to obtain the best fit to profile data using Eqn (5). Specifically we seek the best fit to observed profiles, $R_{\mathrm{obs}}$, of the logarithmic function

$$
R=\ln \left(\frac{\rho}{\left(\rho_{\mathrm{i}}-\rho\right)}\right) .
$$

Since we are interested in the transition region, we optimise over the range $\rho_{1}=500 \mathrm{~kg} \mathrm{~m}^{-3}$ to $\rho_{2}=700 \mathrm{~kg} \mathrm{~m}^{-3}$, unless the record is too short, or the data are too sparse, to make this feasible, in which case the range is adapted slightly. We define a cost function which can be applied to density data with widely differing resolutions and numbers of points in the optimisation range. This is achieved by fitting a third-order polynomial $R_{\mathrm{s}}$ to $R_{\mathrm{obs}}$ so that $N$ height values, $z_{\mathrm{s}}(i)$, for the smoothed profile can be calculated at regular intervals of $5 \mathrm{~kg} \mathrm{~m}^{-3}$ from $\rho_{1}(i=1)$ to $\rho_{2}(i=N)$. Model heights, $z_{\text {model }}(i)$, are calculated at the same intervals. The constant of integration in Eqn (5) is defined so that $R_{\text {model }}=R_{\mathrm{s}}$ at density $\rho_{1}$ and $\rho_{\text {model }}=\rho_{0}$ at the surface $z=0$. Given that Eqn (7) does not apply to the near-surface layer with its strongly 
varying temperature, the model surface intercept density, $\rho_{0}$, will not necessarily be the same as the observed surface density.

The cost function, $\Psi$, is defined as

$$
\Psi=\left(\frac{1}{N} \sum_{i=1}^{N}\left(\frac{\left(z_{\text {model }}(i)-z_{\mathrm{s}}(i)\right)}{z_{\mathrm{s}}(i)},\right)^{2}\right)^{1 / 2}
$$

and the optimum values of $\rho_{\mathrm{T}}$ and $\Delta \rho$ for a given profile (i.e. the local optimum values) are those that minimise $\Psi$ for that profile.

In order to develop physics-based equations for global values of the transition parameters we need to consider the length scale, $\lambda$, of HL(T). The model predicts the mean density $\rho$ over a macroscale element of length $\lambda$, that is, the mean of the varying density $\rho^{\prime}$ within it. We can split the variation into two parts: first the annual and sub-annual fluctuations of amplitude $\approx 50 \mathrm{~kg} \mathrm{~m}^{-3}$ apparent in high-resolution density profiles (e.g. Hörhold and others, 2011) and secondly the slow increase in density from the upper part of the element to the lower part. This will not always be negligible. For a densification rate of $0.05 \mathrm{~m}$ w.e. $\mathrm{a}^{-1}$ and density $500 \mathrm{~kg} \mathrm{~m}^{-3}$, for example, the increase would be $\approx$ $10 \mathrm{~kg} \mathrm{~m}^{-3}$ for $\lambda=1 \mathrm{~m}$.

Within the macroscale element there may also be a variable transition density $\rho_{\text {T }}^{\prime}$ because some layers of the snow are weaker than others. Some of this variability will be annual and subannual, but some will be on a longer timescale. For example, there may be a run of several years with high dust concentration which increases the stage 2 creep rate (Hörhold and others, 2012), followed by several years with lower levels. The choice of $\lambda$ has to be such that this variability is smoothed on the macroscale.

Now we consider what happens as an element of length $\lambda$ moves downwards from the surface. Given a fixed value of $\rho^{\prime}{ }_{\mathrm{T}}$, the macroscale transition zone must extend from the point where the first density peak in the element reaches this value to the point where the last density trough passes it. Thus, a minimum value of the macroscale transition half-width, $\Delta \rho$, is given by the amplitude of $\rho^{\prime}$. A similar argument can be used to determine the effect of varying $\rho_{\text {T }}^{\prime}$ with fixed $\rho^{\prime}$. The minimum value of $\Delta \rho$ is given by the amplitude of $\rho^{\prime}{ }_{\mathrm{T}}$. When the two effects are combined, the minimum value of $\Delta \rho$ is the greater of the two amplitudes. However, it is also the case that the transition zone has to extend for at least a half-cycle in density or strength i.e. from density peak to density trough or from strength trough to strength peak. This implies $\Delta \rho-k_{0} \rho\left(\rho_{\mathrm{i}}-\rho\right) \lambda / 4$ which for large $\lambda$ may become greater than the amplitudes of $\rho^{\prime}$ and $\rho^{\prime}{ }_{\mathrm{T}}$.

For low-accumulation sites, $\Delta \rho$ will be controlled by the amplitude of the annual and sub-annual density fluctuations and the transition region will extend over many annual layers. In this case the length scale of the model can be much less than the width of the transition zone. However, for high-accumulation sites the length scale required to smooth the fluctuations controls the transition width and the two are of the same magnitude. At this stage, if $\lambda$ extends over a fixed number of annual layers, a linear relation will develop between $\Delta \rho$ and $\bar{a}$.

\section{Data}

\subsection{Profiles used in this study}

We have divided the snow density profiles available from the 2020 SUMup database (Montgomery and others, 2018), plus some new profiles yet to be added to SUMup, into groups, depending on the resolution of the data, the length of the record and our judgement of the accuracy of the associated climate data (Appendix A).

At 29 sites very high-resolution density profiles have been obtained using gamma-ray attenuation techniques (Wilhelms,
1996; Breton and others, 2009) to depths well below the transition from stage 1 to stage 2 densification at $z_{\mathrm{T}}$ (Table A1). The mean annual accumulation has been determined by chemical analysis of the core and the mean annual firn temperature has been measured at the site. A further 21 density profiles (Table A2) were collected using a neutron-scattering technique (Morris and Cooper, 2003). These data have a reasonably high resolution of $\approx 3 \mathrm{~cm}$, and $T_{\mathrm{m}}$ and $\bar{a}$ have been measured in situ. The Katie profile, from a borehole near Summit Station, Greenland, is $30 \mathrm{~m}$ long and covers the whole of the transition region. However, the diameter of the hole was relatively large (nominal value $14.9 \mathrm{~cm}$ ) so there is a risk of error in the calculated density if the $5 \mathrm{~cm}$ diameter neutron probe moved from its correct position resting on the wall of the hole. The remaining profiles, collected during the iSTAR traverse across Pine Island Glacier, Antarctica, were obtained from $5 \mathrm{~cm}$ access holes, so this problem did not arise. They are short $(13 \mathrm{~m})$, and therefore may not cover the whole of the transition region, but useful because (1) they cover climatic conditions for which gamma-ray profiles are not available, (2) because some of the profiles come from regions of unusually high velocity divergence and (3) because there are gravimetric measurements from many of the same sites so a comparison between measurement techniques can be made.

Gravimetric density profiles longer than $50 \mathrm{~m}$ have been divided into three groups. We have found 14 profiles for which the average data resolution is $<50 \mathrm{~cm}$ and the climatic data have been measured in situ (Group A, Table A3) and 22 sites with average data resolution $>50 \mathrm{~cm}$ but with good in situ climate data (Group B, Table A4). We have added gravimetric data from the Katie core to Group B, although the record is only $30 \mathrm{~m}$ long, because this is the only site for which we have both neutron scattering and gravimetric data from exactly the same spot. Finally, we have 17 lower-resolution sites (Group C, Table A5) with data which need special attention. This may be because in situ climate data are not available or because we believe errors have arisen in transferring climate data from the primary sources to existing databases.

To avoid over-loading Tables A1 to A5, site positions, citations and comments on any changes we have made are given in the Supplementary material to this paper.

\subsection{Excluded profiles}

There remain a few profiles used in other studies which fall within our general criteria but which are excluded from this study. Two sites (Dominion Range and Newall) have very low accumulation rates for which the Herron and Langway (1980) theory breaks down (because the calculated values of $k_{1}$ is greater than the calculated value of $k_{0}$ ). The density profile from Prospector-Russell Col, Mount Logan (personal communication from D. A. Fisher, 2020) does not show a change in the observed densification rate, so that stage 1 cannot be distinguished from stage 2 . The same is true of the Upstream B profile (important in the development of densification models as it demonstrated the effect of stress-enhancement on stage 2 creep (Alley and Bentley, 1988)). Profiles JARE and JARE11 have anomalously high densities and an apparent hiatus in snow accumulation, perhaps caused by katabatic winds (Kameda and others, 1994). Profiles from Taylor Dome and Law Dome (Dome Summit South, DSS) do not have good density data near the surface. The profile from Site 2, an early US coring site in Greenland, shows an oscillation in density with depth which obscures details of the transition from stages 1 to 2. The accumulation rate for Mizuho S25 given by Spencer and others (2001) comes from a personal communication and may be incorrect. The accumulation rate quoted for Ridge B-C comes from a stratigraphic study over 7 years and is 


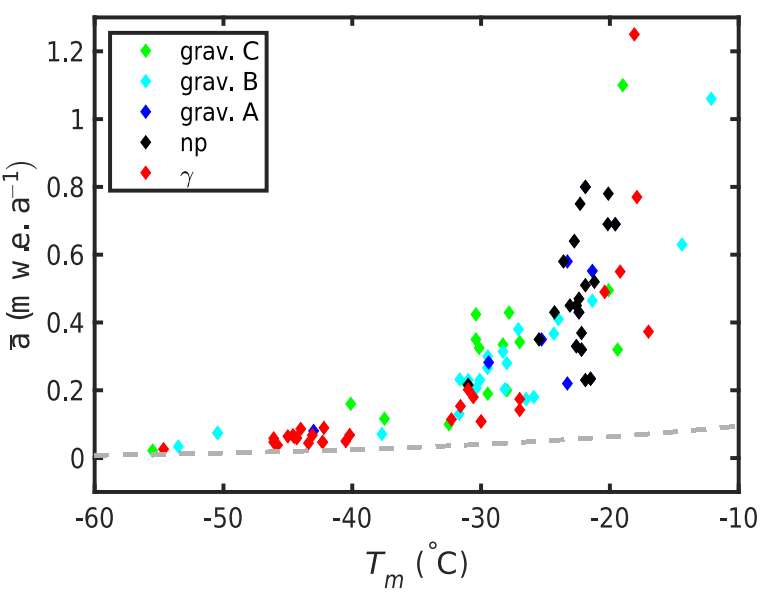

Fig. 1. Distribution of density profiles used in this study with mean annual temperature, $T_{\mathrm{m}}$, and mean annual accumulation, $\bar{a}$. The profiles are divided into groups according to the measurement techniques used (gamma-ray attenuation $(\gamma)$, neutron scattering (np) and gravimetric (grav.)) and the quality of the data (A, B, C). Above the dashed line the Herron and Langway (1980) stage 1 densification rate is greater than the stage 2 rate.

not necessarily the long-term average. This leaves us with 103 profiles, of which 12 were selected by Spencer and others (2001) to calibrate their model, eight were selected by Verjans and others (2020) and a further three were used in both studies.

\subsection{Climatic distribution of the data}

Figure 1 shows the climatic distribution of the data. The gamma-attenuation data span the whole range of $T_{\mathrm{m}}$ and $\bar{a}$, but there are gaps to be filled. The neutron-scattering data fill in the gap between -25 and $-20^{\circ} \mathrm{C}$ but between -40 and $-33^{\circ} \mathrm{C}$ we have to rely on one Group B point (BAS M1) and one Group C point (Mizuho G15). Two Group B points (Dome C and ITASE02_6) fill the gap between -55 and $-46^{\circ} \mathrm{C}$. The gap between 0.8 and $1.2 \mathrm{~m}$ w.e. $\mathrm{a}^{-1}$ is filled by one Group B point (Beethoven Peninsula) and one Group C point (DE08). We use the colour coding introduced in Figure 1 to distinguish the different groups in subsequent figures.

All of the profiles can be used to estimate local values of the transition parameters $\rho_{\mathrm{T}}$ and $\Delta \rho$, although the high-resolution data are expected to give higher precision. The number of profiles which can be used to test the ability of the model to predict $z_{\mathrm{BCO}}$ or DIP is more limited; there are 17 that are long enough in the gamma-attenuation group, 3 in Group A, 16 in Group B and 11 in Group C, a total of 45 . We have found reliable corrections for thinning for only 15 of these. Thus, despite the large number of density profiles now available from the SUMup database, we are still somewhat limited in what can be achieved by their analysis.

\section{Results}

As an example of the results, Figure 2 shows the observed and modelled profiles for core B36/B37 collected at the EPICA deep drilling site in the interior of Dronning Maud Land (EDML) where $T_{\mathrm{m}}=-44.6^{\circ} \mathrm{C}$ and $\bar{a}=0.067 \mathrm{~m}$ w.e. $\mathrm{a}^{-1}$. The best fit across the transition region is obtained with $\rho_{\mathrm{T}}=509 \mathrm{~kg} \mathrm{~m}^{-3}$ and $\Delta \rho=$ $39 \mathrm{~kg} \mathrm{~m}^{-3}$ (Table A1). In the upper $10 \mathrm{~m}$ of the profile, the HL(T) curve follows the HL stage 1 curve. The densification rate then decreases for $\sim 10 \mathrm{~m}$ until the stage 2 rate is reached. The amplitude of the observed density variability decreases with depth, to a minimum just below the transition zone, and then increases through the stage 2 region. Thus this profile displays the 'cross-

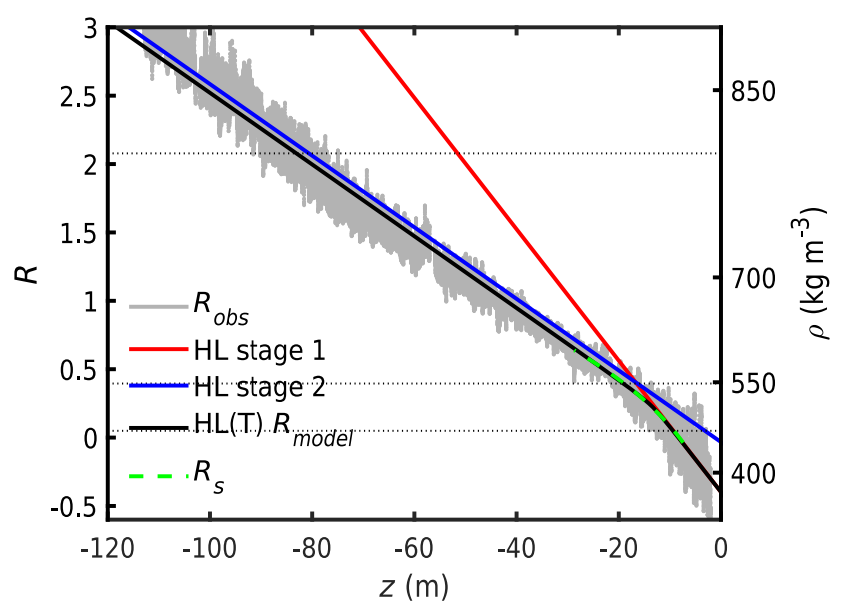

Fig. 2. Observed and modelled profiles of $\left.R=\ln \left(\rho / \rho_{\mathrm{i}}-\rho\right)\right)$ for core B36/B37. The very high-resolution density data $R_{\text {obs }}$ were collected using a gamma-ray attenuation technique. Horizontal dotted lines show the extent of the transition region from stage 1 to stage 2 densification, that is, $\rho_{\mathrm{T}} \pm \Delta \rho$, and the nominal transition to stage 3 . The extended $\mathrm{HL}$ stage 1 and 2 curves cross at $550 \mathrm{~kg} \mathrm{~m}^{-3}$. The parameters of the transition model $\mathrm{HL}(\mathrm{T})$ are optimised to produce the best fit to $R_{\mathrm{s}}$, which is a polynomial fit to the observed data across the transition region.

over process' where through the transition region the densest layers densify at approximately the stage 2 rate, whereas the least dense layers continue to densify at the stage 1 rate (Gerland and others, 1999; Freitag and others, 2004). The value of $\Delta \rho$ reflects the amplitude of the density fluctuations. Using the mean annual accumulation rate of $\bar{a}=0.067 \mathrm{~m}$ w.e. $\mathrm{a}^{-1}$ we calculate that the transition occurs over a period of $\approx 70$ years, so that a relatively large number of annual layers are involved.

Because $\rho_{\mathrm{T}}$ is $<550 \mathrm{~kg} \mathrm{~m}^{-3}$, the transition model can produce an improved fit by lowering the model densities, without changing the HL stage 2 rate. The difference between the BCO heights predicted by the HL(T) and HL models is $\Delta z_{\mathrm{BCO}}=-2.471 \mathrm{~m}$, that is, the transition model predicts a deeper BCO horizon. In fact Figure 2 shows there is a constant horizontal offset of -2.471 $\mathrm{m}$ between the HL(T) model curve and HL stage 2 curve for all depths below the transition region. The transition model gives $D I P=33.144 \mathrm{~m}$ whereas the HL model predicts $D I P=32.062 \mathrm{~m}$. Thus the difference in depth-integrated porosity is $\triangle D I P=$ $1.082 \mathrm{~m}$. Note however that both models will under-estimate $D I P$ because they use mean annual temperature and do not take account of increased densification rates in the surface layer of snow affected by the annual temperature variation.

Although the HL(T) model appears to produce a good estimate of the nominal BCO depth, we note that this is because the observed densification rate is slightly lower than the HL rate for the upper part of stage 2 and then slightly higher in the lower part. This may indicate that there is a gradual transition between stage 2 and stage 3 densification, beginning at a density $<815 \mathrm{~kg} \mathrm{~m}^{-3}$. However, in this paper we focus on modelling the stage $1 /$ stage 2 transition and retain the single nominal value of $\rho_{\mathrm{BCO}}=815 \mathrm{~kg} \mathrm{~m}^{-3}$ so that our results can be compared with those of the Firn Model Intercomparison Experiment (FirnMICE) (Lundin and others, 2017).

Figure 3 shows observed and modelled profiles for a contrasting example. Core B38 was collected at the summit of Halvfarryggen, a small ice dome in coastal Dronning Maud Land, where $T_{\mathrm{m}}=-18.1^{\circ} \mathrm{C}$ and $\bar{a}=1.250 \mathrm{~m}$ w.e. $\mathrm{a}^{-1}$ (Table A1). The best fit over the transition region is obtained with $\rho_{\mathrm{T}}=549$ $\mathrm{kg} \mathrm{m}^{-3}$, very close to the HL transition value of $550 \mathrm{~kg} \mathrm{~m}^{-3}$. However, $\Delta \rho=135 \mathrm{~kg} \mathrm{~m}^{-3}$ and the transition region begins at the surface and extends for $\approx 30 \mathrm{~m}$. This allows the $\mathrm{HL}(\mathrm{T})$ model to produce a better fit to the observed data by raising 


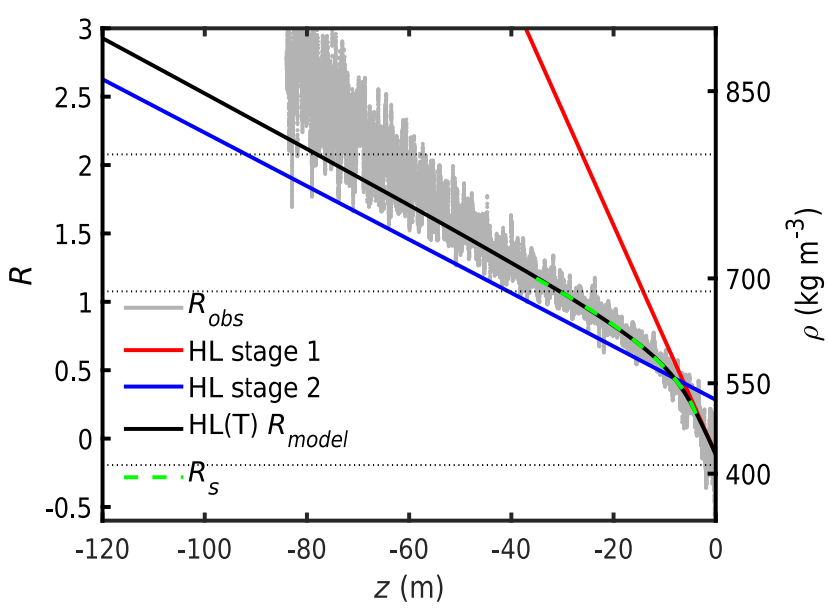

Fig. 3. Observed and modelled profiles of $\left.R=\ln \left(\rho / \rho_{\mathrm{i}}-\rho\right)\right)$ for site B38. The very highresolution density data $R_{\text {obs }}$ were collected using a gamma-ray attenuation technique. Horizontal dotted lines show the extent of the transition region from stage 1 to stage 2 densification, that is, $\rho_{\mathrm{T}} \pm \Delta \rho$, and the nominal transition to stage 3. The extended $\mathrm{HL}$ stage 1 and 2 curves cross at $550 \mathrm{~kg} \mathrm{~m}^{-3}$. The parameters of the transition model $\mathrm{HL}(\mathrm{T})$ are optimised to produce the best fit to $R_{\mathrm{s}}$, which is a polynomial fit to the observed data across the transition region.

the model densities without changing the HL stage 2 rate. In this case $\Delta z_{\mathrm{BCO}}=13.689 \mathrm{~m}$ and $\Delta D I P=-4.201 \mathrm{~m}$, that is the transition model predicts a shallower BCO horizon and a decreased value of DIP. Again, we note that the HL(T) and HL model values of DIP, 27.262 and $31.463 \mathrm{~m}$ respectively, will be under-estimates of the true value.

The amplitude of the density fluctuations in the upper part of this profile is less than half of the optimised value of $\Delta \rho$, suggesting that in this case the scale length $\lambda$ has become the controlling factor. Using the mean annual accumulation rate of $\bar{a}=1.25 \mathrm{~m}$ w.e. $\mathrm{a}^{-1}$ we calculate that the transition occurs over a period $\sim 10$ years, suggesting decadal variations in $\rho^{\prime}{ }_{\mathrm{T}}$. A dust concentration profile for B38 is available (Schmidt and others, 2014) and shows both annual and multi-year variability. This may be the explanation for the variations in $\rho_{\mathrm{T}}^{\prime}$. However, we note also that, if the actual stage 2 densification rate is higher than the HL rate, the value of $\Delta \rho$ will have to increase to compensate and vice versa. Thus $\Delta \rho$ could also include a component arising from uncertainty in $k_{1}^{*}$.

In both these examples the fit below the transition region would be improved by optimising the stage 2 densification rate or even allowing it to vary with depth. However, our object is not to produce the best possible simulation of individual profiles, but rather to gain insight into how we might derive global values of $\rho_{\mathrm{T}}$ and $\Delta \rho$ and to quantify the improvement produced by incorporating them into the HL model. These are therefore the only parameters we allow to vary.

For individual profiles, the goodness-of-fit in the transition region is given by the cost function $\Psi$. Figures showing the variation of $\Psi$ with $\rho_{\mathrm{T}}$ and $\Delta \rho$ are given in the Supplementary material for sites $\mathrm{B} 36 / \mathrm{B} 37$ and $\mathrm{B} 38$. In both cases there is a simple minimum and $\Psi$ is more sensitive to $\rho_{\mathrm{T}}$ than $\Delta \rho$. For B36/B37, $\Psi_{\min }=0.0124$ and $\partial \Psi / \partial \rho_{\mathrm{T}} \approx 3 \partial \Psi / \partial \Delta \rho$. For $\mathrm{B} 38, \Psi_{\min }=0.0093$ and $\partial \Psi / \partial \rho_{\mathrm{T}} \approx 4.5 \partial \Psi / \partial \Delta \rho$. In general, values of $\Psi_{\min }$ range from 0.0034 for the Vostok profile (Table A5) to 0.1784 for DML96C07_39 (B39) (Table A1).

\subsection{Estimation of the uncertainty in model parameters}

Two profiles were obtained from exactly the same point at the Katie site near Summit Camp, Greenland. A core was extracted and segments weighed to provide a gravimetric profile, and the

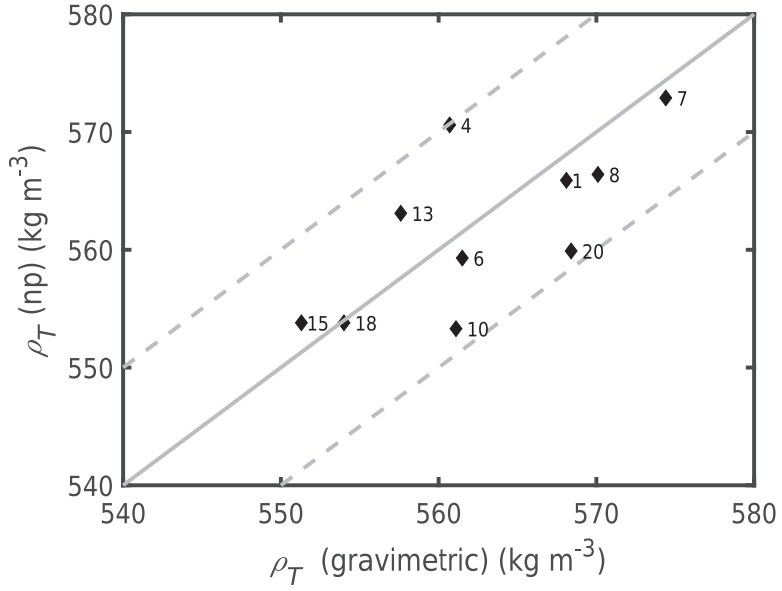

Fig. 4. Best value of $\rho_{\mathrm{T}}$ from neutron scattering density profiles at 10 iSTAR sites as a function of the best value from gravimetric profiles nearby. The solid line shows a 1:1 relationship and dotted lines indicate an uncertainty of $\pm 10 \mathrm{~kg} \mathrm{~m}^{-3}$.

resulting borehole was profiled using a neutron probe. The value of $\bar{a}$ was derived by counting annual density peaks for the neutron scattering profile and by chemical analysis of a range of seasonally varying elements for the gravimetric profile (Hawley and others, 2008) leading to two slightly different values, $0.216 \mathrm{~m}$ w.e. $\mathrm{a}^{-1}$ and $0.23 \mathrm{~m}$ w.e. $\mathrm{a}^{-1}$ respectively. In this particular case we have the opportunity to assess the uncertainty in the optimised values of the model parameters arising from the use of different measurement techniques. The differences in best estimates for $\rho_{\mathrm{T}}, \Delta \rho$ and $\rho_{0}$ are 14,19 and $15 \mathrm{~kg} \mathrm{~m}^{-3}$, respectively (Tables A2 and A4). An increase in $\Delta \rho$ is accompanied by a decrease in $\rho_{\mathrm{T}}$.

Pairs of profiles were also obtained at 10 sites along the iSTAR traverse across Pine Island Glacier, Antarctica. Cores were extracted close to boreholes where neutron probe profiles had been obtained the previous year (Tables A2 and A3). These data allow the effect of local spatial variability plus different measurement techniques to be assessed. Figure 4 shows that the optimum values of $\rho_{\mathrm{T}}$ for each site differ by $10 \mathrm{~kg} \mathrm{~m}^{-3}$ or less; slightly less than the difference of $14 \mathrm{~kg} \mathrm{~m}^{-3}$ found at the Katie site, where the neutron scattering profile is likely to be less accurate than those from the iSTAR sites.

Figure 5 shows that the optimised values of $\Delta \rho$ for each site differ by up to $40 \mathrm{~kg} \mathrm{~m}^{-3}$, with the neutron scattering values tending to be greater than the gravimetric values. This is because the neutron scattering profiles are short and do not define the extent of the transition zone as accurately as the longer gravimetric profiles. Finally Figure 6 shows that the values of $\rho_{0}$ chosen for the two profiles at each site differ by up to $7 \mathrm{~kg} \mathrm{~m}^{-3}$. If there is any error in matching the observed and modelled curves at density $\rho_{1}$ to determine the constant of integration (Section 2), this will affect best estimates of $\rho_{0}$ and $\rho_{\mathrm{T}}$ in the same way. We find no correlation between $\left[\rho_{0}\right.$ (gravimetric) $\left.-\rho_{0}(\mathrm{np})\right]$ and $\left[\rho_{\mathrm{T}}\right.$ (gravimetric) $\left.-\rho_{\mathrm{T}}(\mathrm{np})\right]$ so conclude that this potential systematic error is not important.

We proceed on the assumption that $\approx \pm 10 \mathrm{~kg} \mathrm{~m}^{-3}$ is a reasonable estimate for the uncertainty in optimised values of $\rho_{\mathrm{T}}$ and $\rho_{0}$ for all the profiles and estimate the uncertainty in $\Delta \rho$ as $\approx \pm 40 \mathrm{~kg} \mathrm{~m}^{-3}$ for the short iSTAR neutron scattering profiles and $\approx \pm 20 \mathrm{~kg} \mathrm{~m}^{-3}$ for the longer profiles. To set these estimates in context we note that the expected random error in the neutron probe density measurements is $\approx 2 \%$ and the systematic error arising from a $5 \%$ error in borehole diameter would be a further 2\% (Morris and Wingham, 2014). With these uncertainties we can see from Table 1 that the optimised values (which cannot 


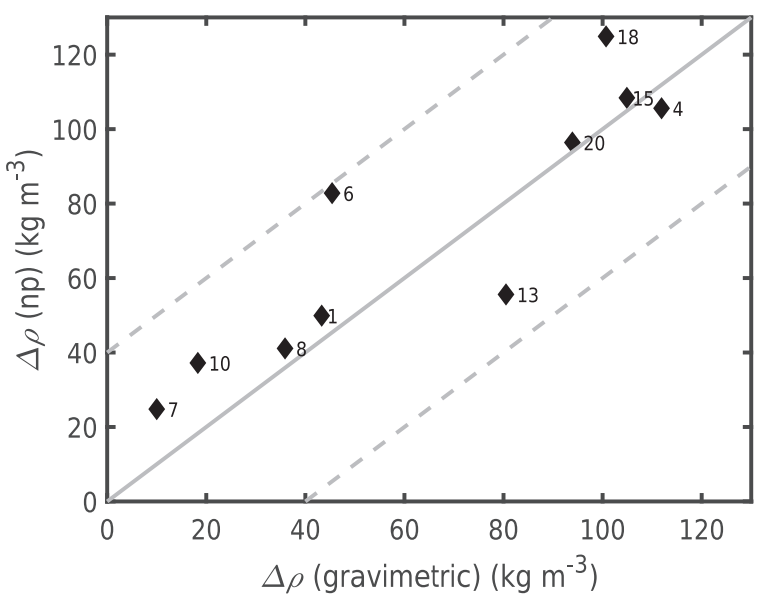

Fig. 5. Best value of $\Delta \rho$ from neutron scattering density profiles at 10 iSTAR sites as a function of the best value from gravimetric profiles nearby. The solid line shows a 1:1 relationship and dotted lines indicate an uncertainty of $\pm 40 \mathrm{~kg} \mathrm{~m}^{-3}$.

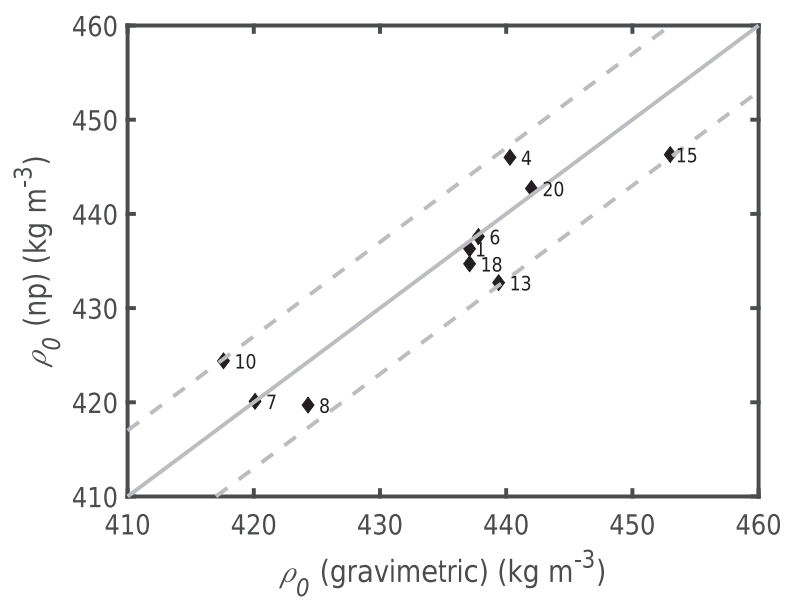

Fig. 6. Best value of $\rho_{0}$ from neutron scattering density profiles at 10 iSTAR sites as a function of the best value from gravimetric profiles nearby. The solid line shows a 1:1 relationship and dotted lines indicate an uncertainty of $\pm 7 \mathrm{~kg} \mathrm{~m}^{-3}$.

be negative) are consistent for the pair of profiles B36/B37 and BAS ISOL (both from the EDML site at Kohnen Station), for the pair of profiles B25 and T1 (separated by $5 \mathrm{~km}$ on Berkner Island) and for the pair of profiles WDC06A and ITASE00_1 (separated by $21 \mathrm{~km}$ on the WAIS Divide). The climate parameters for each pair are the same, or very similar. The two sites from the Dyer Plateau have not been included in Table 1 because there is a significant difference in mean annual accumulation, despite their proximity.

\subsection{Surface intercept density}

Figure 7 shows the surface intercept density generally increases with mean annual temperature and accumulation, as expected. However, within the temperature range of -33 to $-20^{\circ} \mathrm{C}$ and the accumulation range of 0.1 to $0.5 \mathrm{~m}$ w.e. $\mathrm{a}^{-1}$ the variation in $\rho_{0}$ is considerably larger than the estimated uncertainty in individual values. The lower values come from sites in north and central Greenland and from the Devon Ice Cap, the higher values from Antarctica, suggesting a difference in type of snow between these areas. The two groups appear to correspond to the $\mathrm{L}$ and $\mathrm{H}$ groups of ice cores identified by Salamatin and others (2009) on the basis of their characteristic microstructural parameters. For similar temperature and accumulation rates the $\mathrm{L}$ group has a lower surface density than the $\mathrm{H}$ group.
Table 1. Optimised parameters for profile pairs

\begin{tabular}{lcccccc}
\hline Sites & $\begin{array}{c}\text { Separation } \\
\mathrm{km}\end{array}$ & $\begin{array}{c}T_{\mathrm{m}} \\
{ }^{\circ} \mathrm{C}\end{array}$ & $\begin{array}{c}\bar{a} \\
\mathrm{~m} \mathrm{w.e.} \mathrm{a}^{-1}\end{array}$ & $\begin{array}{c}\rho_{\mathrm{T}} \\
\mathrm{kg} \mathrm{m}^{-3}\end{array}$ & $\begin{array}{c}\Delta \rho \\
\mathrm{kg} \mathrm{m}^{-3}\end{array}$ & $\begin{array}{c}\rho_{0} \\
\mathrm{~kg} \mathrm{~m}^{-3}\end{array}$ \\
\hline B36/B37 & 0 & -44.6 & 0.067 & $509 \pm 10$ & $39 \pm 20$ & $368 \pm 10$ \\
BAS ISOL & & -44.6 & 0.067 & $507 \pm 10$ & $28 \pm 20$ & $362 \pm 10$ \\
B25 & 5 & -27.6 & 0.174 & $532 \pm 10$ & $9(+20,-9)$ & $390 \pm 10$ \\
T1 & & -26.5 & 0.174 & $544 \pm 10$ & $1(+20,-1)$ & $382 \pm 10$ \\
WDC06A & 21 & -31.0 & 0.202 & $542 \pm 10$ & $43 \pm 20$ & $428 \pm 10$ \\
ITASE00_1 & & -31.1 & 0.218 & $541 \pm 10$ & $44 \pm 20$ & $410 \pm 10$ \\
\hline
\end{tabular}
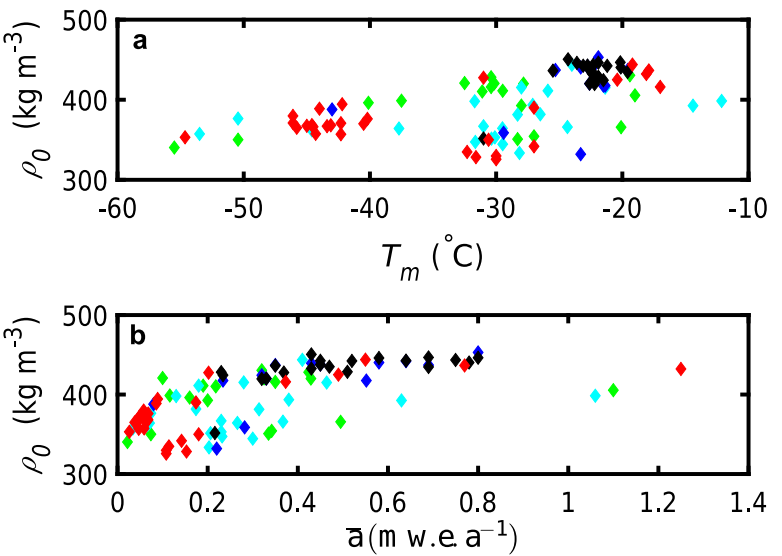

Fig. 7. Variation of surface intercept density, $\rho_{0}$, with (a) mean annual temperature, $T_{\mathrm{m}}$, and (b) mean annual accumulation, $\bar{a}$, for the density profiles used in this study. The data are divided into groups according to the measurement techniques used and the quality of the density data (Section 3.3).

\subsection{The transition density}

Figure 8 shows that the optimised values of the transition density, $\rho_{\mathrm{T}}$, for individual profiles increase with increasing mean annual temperature, accumulation and surface intercept density. Values range from 499 to $581 \mathrm{~kg} \mathrm{~m}^{-3}$; a range $\sim 8$ times greater than the estimated uncertainty in individual values. The depth at which the transition density is reached, $-z_{\mathrm{T}}$, ranges from 5 to $22 \mathrm{~m}$ below the surface, so that for some sites the transition occurs above the nominal $10 \mathrm{~m}$ penetration depth for the annual temperature wave. The water-equivalent depth at the transition, $q_{\mathrm{T}}$, ranges from 2.5 to $9.5 \mathrm{~m}$ w.e. that is, an overburden pressure range of 25 to $93 \mathrm{kPa}$ ( 0.25 to 0.93 bar).

\subsection{The transition range}

Figure 9 is less clear, since there is more variability in $\Delta \rho$. Values of the transition half-width range from 0 to $135 \mathrm{~kg} \mathrm{~m}^{-3}$, that is 3-7 times greater than the estimated uncertainties in individual values. Of the sites with $\Delta \rho \geq 100 \mathrm{~kg} \mathrm{~m}^{-3}$, four have long records, so the value will be well-constrained. Only iSTAR sites 17 and 21 (Table A2) have high values which might be an artefact of the short record. All the highest values of the transition half-width are for profiles with high accumulation, but overall the correlation between $\Delta \rho$ and $\bar{a}$ is weak.

\section{Discussion}

\subsection{Physical interpretation of the transition parameters}

For some profiles it is possible to compare the optimised parameters of the HL(T) model with direct observations of the range of the transition region. For example, Hörhold and others (2012) use the variability of the very high-resolution gamma-ray 


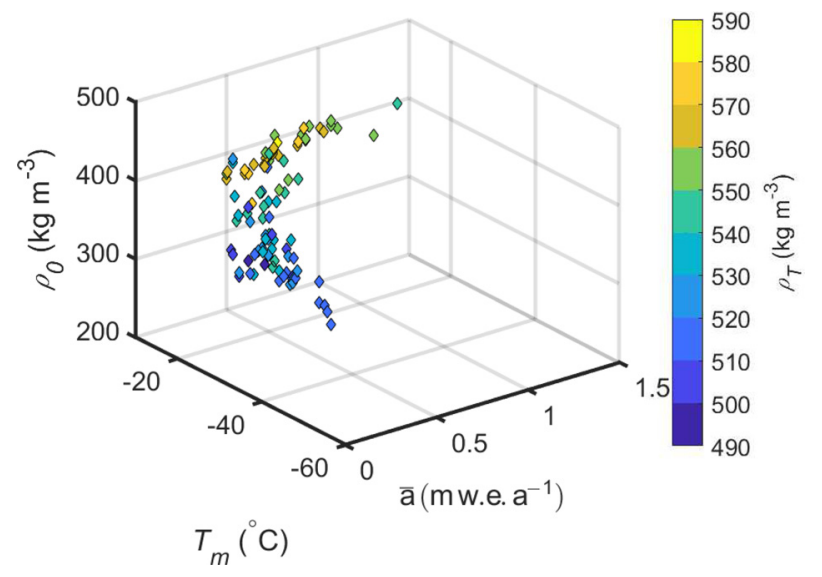

Fig. 8. Optimised values of the transition density, $\rho_{\mathrm{T}}$, for individual profiles as a function of mean annual temperature, $T_{\mathrm{m}}$, mean annual accumulation, $\bar{a}$ and the surface intercept density, $\rho_{0}$.

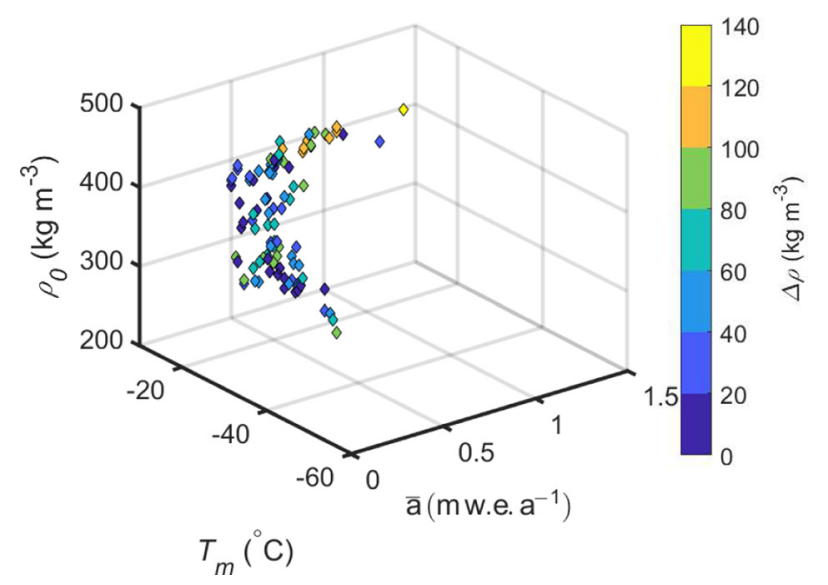

Fig. 9. Optimised values of the transition half-width, $\Delta \rho$, for individual profiles as a function of mean annual temperature, $T_{\mathrm{m}}$, mean annual accumulation, $\bar{a}$ and the surface intercept density, $\rho_{0}$.

attenuation data to determine the position and nature of the transition in their profiles. They observed a weak transition in the slope at densities between 550 and $580 \mathrm{~kg} \mathrm{~m}^{-3}$ for the highaccumulation sites DML95, DML97 and DML96C07_39 (B39) where we have transition regions with $\rho_{\mathrm{T}}=(550 \pm 10),(557 \pm 10)$, $(552 \pm 10) \mathrm{kg} \mathrm{m}^{-3}$ and $\Delta \rho=(74 \pm 20),(38 \pm 20),(98 \pm 20) \mathrm{kg} \mathrm{m}^{-3}$, respectively. They considered that low-accumulation profiles ngt37C95.2 (B26), ngt42c95_2 (B29) and B36/B37 (EDML) showed this transition at much lower densities, below $500 \mathrm{~kg}$ $\mathrm{m}^{-3}$. We have $\rho_{\mathrm{T}}=(513 \pm 10),(532 \pm 10)$ and $(509 \pm 10) \mathrm{kg} \mathrm{m}^{-3}$, respectively, with $\Delta \rho=(68 \pm 20),(42 \pm 20)$ and $(39 \pm 20) \mathrm{kg} \mathrm{m}^{-3}$. However, Hörhold and others (2012) considered that the BER11C95_25 (B25) profile showed a distinct change in the slope at $\sim 550 \mathrm{~kg} \mathrm{~m}^{-3}$, whereas we have found a relatively sharp transition $\left(\Delta \rho=(9 \pm 20) \mathrm{kg} \mathrm{m}^{-3}\right)$ at the lower value of $\rho_{\mathrm{T}}=(532$ $\pm 10) \mathrm{kg} \mathrm{m}^{-3}$.

Another example comes from the Katie site in Greenland. The transition parameters determined for the neutron probe profile indicate a transition zone that begins at $z=-9.5 \mathrm{~m}$ and ends at $z=-12.6 \mathrm{~m}$. Optical stratigraphy measurements in the same borehole (Hawley and Morris, 2006) show a reduced correlation between de-trended density and returned brightness in the window extending from 10 to $12.5 \mathrm{~m}$ below the surface. The authors attribute this to a gradual change in microstructure between stage 1 and stage 2 densification. The density variability also decreases over this range. These are encouraging indications that $\rho_{\mathrm{T}}$ and $\Delta \rho$ are physically based parameters.

\subsection{Densification parameters}

At two sites Hörhold and others (2012) comment that the HL model fails. They report that the EDC2 density profile shows no abrupt change at all and density is over-predicted using $T_{\mathrm{m}}=-53^{\circ} \mathrm{C}$ and $\bar{a}=0.025 \mathrm{~m}$ w.e. $\mathrm{a}^{-1}$ to calculate densification rates. However, with revised values of $T_{\mathrm{m}}=-54.65^{\circ} \mathrm{C}$ and $\bar{a}=0.0261$ from Parrenin and others (2007) we are able to model the profile quite well with $\rho_{\mathrm{T}}=514 \mathrm{~kg} \mathrm{~m}^{-3}$ and $\Delta \rho=63$ $\mathrm{kg} \mathrm{m}^{-3}$. In this case it may be that uncertainty in the climate data is the source of the problem. The second example is the DML94C07_38 (B38) profile (Fig. 3). Hörhold and others (2012) comment that this shows a transition density close to $600 \mathrm{~kg} \mathrm{~m}^{-3}$ and that stage 2 densities are under-predicted. Using the same climate data, we find the best value of $\rho_{\mathrm{T}}$ is lower, at $(549 \pm 10) \mathrm{kg} \mathrm{m}^{-3}$ but that this is combined with a high value of $\Delta \rho=(135 \pm 20) \mathrm{kg} \mathrm{m}^{-3}$ which extends the transition zone well over $600 \mathrm{~kg} \mathrm{~m}^{-3}$. The stage 2 densities are still slightly under-predicted, but the fit is much improved. Thus we have no reason to suppose that the value of the densification parameter $k_{1}$ is greatly in error.

Although we are primarily concerned with dry snow densification, firn from the warmer sites in our dataset is likely to contain some ice layers formed when summer meltwater refreezes in the corresponding annual layer. For example, Abram and others (2013) report an average melt layer content of $4.9 \%$ in the James Ross Island ice core and Koerner (1977) gives an average of $8 \%$ for a core from the summit of Devon Ice Cap. Reeh and others (2005) show that the effect of these layers is to distort the density profile predicted by HL. We have not taken this distortion into account explicitly. However, the method we use to fit $\mathrm{HL}$ and $\mathrm{HL}(\mathrm{T})$ to the profiles (Section 2) means that the models are constrained to fit the data at the point where the density reaches $\rho_{1}$ (usually $500 \mathrm{~kg} \mathrm{~m}^{-3}$ ). Any distortion above this level does not affect the modelling. Any effect of melt layers on the observed stage 2 densification rate below this level is not immediately apparent; our results show the HL value of $k_{1}$ produces a good fit for the James Ross Island and Devon Island density profiles for example.

\subsection{Prediction of the $B C O$ horizon}

In order to assess the general performance of $\mathrm{HL}(\mathrm{T})$, we compare its predictions of the nominal $\mathrm{BCO}$ depth, i.e. the depth at which the density reaches a value of $815 \mathrm{~kg} \mathrm{~m}^{-3}$, with those of the benchmark HL model. This is one of the criteria used to assess model performance in FirnMICE (Lundin and others, 2017), but relies on the assumption that stage 2 densification extends at least to this density. This is a reasonable assumption but may not always be true. Although FirnMICE made relative comparisons between models, we make an absolute assessment by comparing model predictions with observed data. We obtain the observed BCO depth by fitting a smooth, monotonically increasing curve to the measured densities in the BCO region. Depending on the resolution of the data, the uncertainty in this observed value can be up to $\approx 1 \mathrm{~m}$. Figure 10 shows the difference between the predicted and observed horizons, $\left(z_{\text {model }}\right)$ всо and $\left(z_{s}\right)$ всо, for the two models. The uncertainty in this difference will be at least as great as the uncertainty in $\left(z_{\mathrm{s}}\right)$ BCO. For example, the deepest BCO depths are found at the South Pole 2001 (labelled in Fig. 10) and ITASE02_6 sites. These sites are separated by $\approx 8 \mathrm{~km}$ and have the same climate, but there is $3 \mathrm{~m}$ difference in their values of $\left(z_{\mathrm{s}}\right)$ всо. This explains at least part of the 


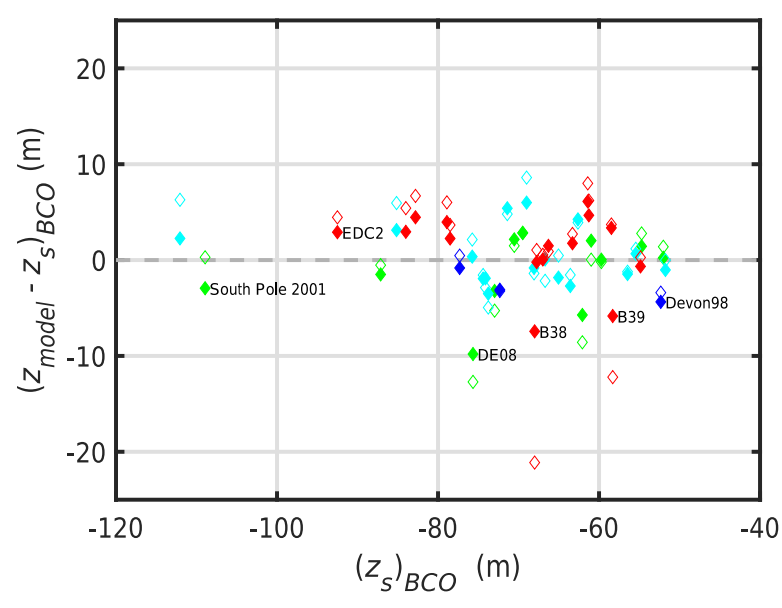

Fig. 10. Difference between predicted and observed BCO heights. Predicted heights are calculated using the $\mathrm{HL}$ model $(\diamond)$, and the $\mathrm{HL}(\mathrm{T})$ model with local optimised values of $\rho_{\mathrm{T}}$ and $\Delta \rho(\diamond)$. The points are divided into groups according to the measurement techniques used and the quality of the density data (Section 3.3).

$\approx 5 \mathrm{~m}$ difference in $\left[\left(z_{\text {model }}\right)_{\text {всO }}-\left(z_{\mathrm{s}}\right)_{\text {вCO }}\right]$. The mean difference for the 45 sites for which we have observed data is $0.21 \mathrm{~m}$ for the HL model and $0.09 \mathrm{~m}$ for the transition model. The values are not significantly different. However, the r.m.s. of the differences, which is a measure of the overall performance of the model, is $37 \%$ less for the HL(T) model $(3.51 \mathrm{~m})$ than for the HL model $(5.60 \mathrm{~m})$. The improvement is particularly marked for B38 (Halvfarryggen Ridge) and B39 (Søråsen Ridge). Nevertheless, the predicted $\mathrm{BCO}$ depth still remains too low for these sites, and for two other sites with relatively shallow ice depths, DE08 (Law Dome) and Devon98 (Devon Ice Cap).

This suggests that the predictions can be improved by the subtraction of a factor, $\theta_{\mathrm{BCO}}$, from $\left(z_{\text {model }}\right)$ BCO to take account of the thinning effect of horizontal flow divergence, $\dot{\varepsilon}_{\mathrm{H}}$, in the firn. Following Raymond and others (1996) we make the assumption that $\dot{\varepsilon}_{\mathrm{H}}$ is constant for $\rho \leq 815 \mathrm{~kg} \mathrm{~m}^{-3}$ and (because the ice is incompressible) equal and opposite to the vertical strain rate at the ice-firn boundary, $\dot{\varepsilon}_{z z}$. For some of the ice cores previous researchers have derived a thinning function, $\Gamma$, as a function of depth by detailed ice flow modelling. This gives us a method of estimating $\dot{\varepsilon}_{\mathrm{H}}$, since, by definition,

$$
\dot{\varepsilon}_{z z}=\frac{1}{\Gamma} \frac{\mathrm{d} \Gamma}{\mathrm{d} \tau}=-\bar{a} \frac{\rho_{\mathrm{w}}}{\rho_{\mathrm{i}}} \frac{\mathrm{d} \Gamma}{\mathrm{d} z}
$$

where $\tau$ is time from deposition and $\rho_{\mathrm{w}}$ is the density of water. At a divide it is also possible to use the Nye approximation (Nye, 1963)

$$
\dot{\varepsilon}_{z z} \approx-\bar{a} \frac{\rho_{\mathrm{w}}}{H \rho_{\mathrm{i}}}
$$

where $H$ is the depth of ice. We use this method for profiles from coastal ice domes if a thinning function has not been reported in the literature. Note however that the Nye approximation will probably underestimate $\dot{\varepsilon}_{z z}$ (Paterson and Waddington, 1984).

The thinning correction factor

$$
\theta_{\mathrm{BCO}}=z_{\mathrm{BCO}}-\int_{0}^{z_{\mathrm{BCO}}} \exp \left(-\dot{\varepsilon}_{\mathrm{H}} \tau\right) \mathrm{d} z
$$

is estimated by using the HL model to derive stage 1 and stage 2 expressions for $\tau$ and $\mathrm{d} z$ (Morris and others, 2017). A similar method has been used by Horlings and others (2020). The

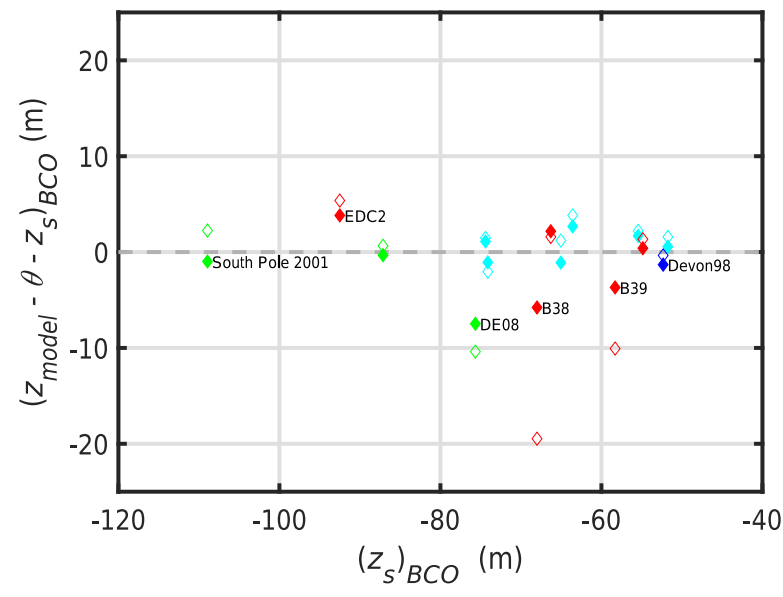

Fig. 11. Difference between predicted and observed BCO heights, corrected for thinning. Predicted heights are calculated using the $\mathrm{HL}$ model $(\diamond)$, and the $\mathrm{HL}(\mathrm{T})$ model with local best values of $\rho_{\mathrm{T}}$ and $\Delta \rho(\diamond)$. The points are divided into groups according to the measurement techniques used and the quality of the density data (Section 3.3).

resulting indefinite integrals can be expressed analytically in terms of hypergeometric functions. Values of $\dot{\varepsilon}_{\mathrm{H}}$ and $\theta_{\mathrm{BCO}}$ are shown in the Supplementary material for nine deep ice cores for which we have found published thinning functions and six cores taken near the summit of ice domes. The thinning correction ranges from $<1 \mathrm{~m}$ in the interior of the large ice sheets to $\approx 3 \mathrm{~m}$ for the small ice domes.

Figure 11 shows the effect of the thinning correction. The predictions for the four coastal ice dome sites are improved, but profiles DE08, B38 and B39 are still outliers. On the other hand, both models predict $\mathrm{BCO}$ depths for the EDC2 core which are too shallow and this difference is made worse by application of the thinning correction. The mean difference for all sites becomes -1.39 $\mathrm{m}$ for the HL model and $-0.62 \mathrm{~m}$ for the HL(T) model; the r.m.s. value is increased to $6.62 \mathrm{~m}$ for the HL model and decreased to $3.05 \mathrm{~m}$ for the HL(T) model. The overall conclusion remains: predictions of the nominal BCO depth are improved by modelling the transition between stage 1 and stage 2 for each profile rather than specifying an abrupt transition at a fixed density. For this reduced set of 15 profiles the improvement is $54 \%$.

\subsection{Prediction of DIP}

We are not able to compare observed and modelled values of DIP because we do not model the surface layer of snow affected by the annual variation in temperature. However, it is possible to calculate the change in DIP produced by including a transition zone. We find that $\triangle D I P \approx-0.34 \Delta z_{\mathrm{BCO}}$ and ranges from $-4.2 \mathrm{~m}$ at the warm coastal site $\mathrm{B} 38$ to $+1.7 \mathrm{~m}$ at the cold interior site, ITASE02_6. In general, HL(T) predicts a smaller DIP than HL for warm, high-accumulation sites and a larger DIP than HL for cold, low-accumulation sites (Tables A1 to A5).

\subsection{Derivation of global parameters}

So far we have derived local best values for the transition parameters by fitting the model to the transition regions of single density profiles. The next step in developing the HL(T) model is to derive global expressions for the two parameters so that individual values can be predicted a priori. In principle these expressions could be implicit, for example relating $\rho_{\mathrm{T}}$ to conditions at the transition such as the overburden stress, $\sigma$, the waterequivalent depth, $q_{\mathrm{T}}$, the time since deposition, $\tau_{\mathrm{T}}$, and the total strain experienced, $\varepsilon_{\mathrm{T}}$, or explicit, using variables such as $T_{\mathrm{m}}, \bar{a}$ 
Table 2. Pearson's $r$ for 73 profiles

\begin{tabular}{lccccc}
\hline & $\rho_{\mathrm{T}}$ & $\Delta \rho$ & & $\rho_{\mathrm{T}}$ & $\Delta \rho$ \\
\hline$\varepsilon_{\mathrm{T}}$ & 0.53 & - & $k_{0}-k_{1}$ & 0.71 & 0.54 \\
$q_{\mathrm{T}}$ & -0.51 & - & $\rho_{0}$ & 0.80 & 0.26 \\
$\tau_{\mathrm{T}}$ & -0.45 & - & $\bar{a}$ & 0.67 & 0.61 \\
\hline
\end{tabular}

and $\rho_{0}$ which can be specified without knowledge of $\rho_{\mathrm{T}}$ or $\Delta \rho$. We select 73 profiles, excluding neutron probe profiles from sites where gravimetric data are available and profiles which do not have at least 10 measurements in the transition zone, and calculate Pearson's linear correlation function, $r$, between variables. Table 2 shows $r$-values for the statistically significant cases with $p$-value $\leq 0.05$. Our data do not show any strong correlations between the transition density and transition conditions although, as suggested by Arnaud and others (1998), we do see that $\rho_{\mathrm{T}}$ decreases with increasing $q_{\mathrm{T}}$.

Although implicit equations might be expected to best represent the physical processes involved in the transition, more promising results are obtained by deriving simple, physically based, explicit expressions for $\rho_{\mathrm{T}}$ and $\Delta \rho$. We begin with the concept that grain-boundary sliding can continue for longer if powerlaw creep is more difficult to initiate, that is, that the transition density should increase with the difference in densification rates, $\left(k_{0}-k_{1}\right)$. We further suppose that the particular combination of grain size and shape, grain bonding and layering that occurs at a given site, will also influence the transition parameters. We use $\rho_{0}$, the surface intercept density, to discriminate between types of snow. Finally, as discussed in Section 2, we suppose that $\Delta \rho$ will have a threshold value set by the magnitude of the annual and sub-annual fluctuations in density and then increase with $\bar{a}$ at higher accumulation rates. Table 2 shows higher $r$-values for these variables.

We select the two most significant variables, $\left(k_{0}-k_{1}\right)$ and $\rho_{0}$, to derive an expression for the global value of the transition density, $\rho_{\mathrm{TG}}$. Figure 12 shows the local values of $\rho_{\mathrm{T}}$ as a function of these variables against the background of the best linear fit to 29 evenly spaced points from the high-resolution groups, namely

$$
\begin{aligned}
\rho_{\mathrm{TG}}= & {\left[(359 \pm 400) \mathrm{kg} \mathrm{m}^{-3} \mathrm{~m} \text { w.e. }\right]\left(k_{0}-k_{1}\right) } \\
& +[(0.300 \pm 0.156)] \rho_{0} \\
& +\left[(404 \pm 51) \mathrm{kg} \mathrm{m}^{-3}\right] \quad r^{2}=0.72
\end{aligned}
$$

The contours are shown at intervals of $10 \mathrm{~kg} \mathrm{~m}^{-3}$, the estimated uncertainty in individual points. The mean difference between global and local values is $-1 \mathrm{~kg} \mathrm{~m}^{-3}$. The r.m.s. of the differences is $12 \mathrm{~kg} \mathrm{~m}^{-3}$ for the high-resolution data and slightly greater, at $14 \mathrm{~kg} \mathrm{~m}^{-3}$, for Groups B and C, as we might expect. The extreme values of $\left|\rho_{\mathrm{TG}}-\rho_{\mathrm{T}}\right| \approx 30 \mathrm{~kg} \mathrm{~m}^{-3}$ come from Groups B and C. The points fall into two groups separated by $\approx 60 \mathrm{~kg} \mathrm{~m}^{-3}$ in $\rho_{0}$ at the same value of $\left(k_{0}-k_{1}\right)$. In Section 4.2 we compared these groups to the $\mathrm{H}$ and L groups defined by Salamatin and others (2009), who suggested that different wind regimes produce different surface densities in otherwise similar climatic conditions. The corresponding difference in $\rho_{\mathrm{TG}}$ of $\approx 18 \mathrm{~kg} \mathrm{~m}^{-3}$ is comparable to the difference of $(33 \pm 8) \mathrm{kg} \mathrm{m}^{-3}$ in critical density values for $\mathrm{H}$ and L group profiles reported by Salamatin and Lipenkov (2008).

It has been suggested (Alley and Bentley, 1988; Riverman and others, 2017) that $k_{1}$ may increase in areas of high strain rate. If this is so, we might expect a decrease in $\rho_{\mathrm{T}}$ with increasing $\dot{\epsilon}_{\mathrm{H}}$. Horizontal divergences for the iSTAR sites range up to a relatively high value of $8.9 \times 10^{-3} \mathrm{a}^{-1}$ (Morris and others, 2017) but we find no evidence of correlation between $\left[\rho_{\mathrm{T}}-\rho_{\mathrm{TG}}\right]$ and $\dot{\epsilon}_{\mathrm{H}}$ for these data.

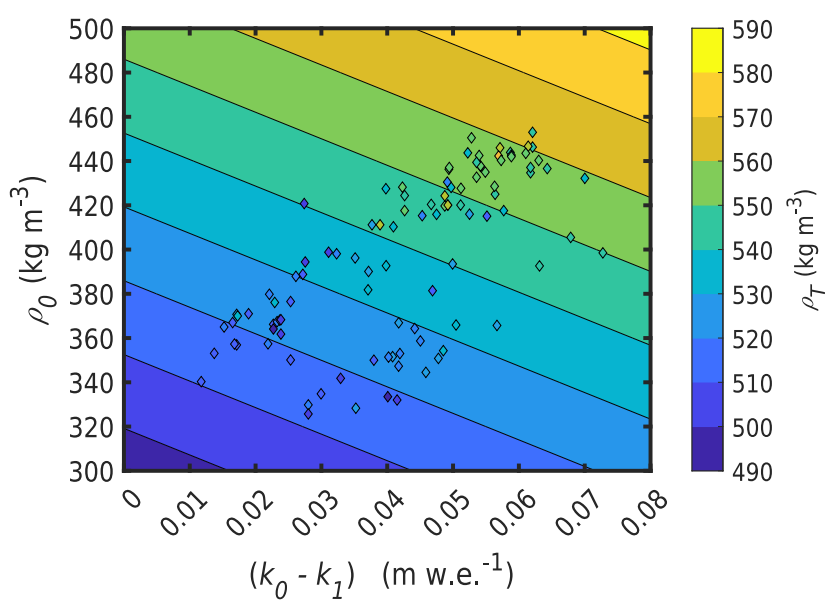

Fig. 12. Optimised values of the transition density $\rho_{\mathrm{T}}$ as a function of the difference in densification rates $\left(k_{0}-k_{1}\right)$ and the surface intercept density, $\rho_{0}$. The contours are derived from a first-order polynomial fit to 29 selected values.

In Figure 13 the transition half-widths for the 73 selected profiles are shown, with their estimated errors, as a function of $\bar{a}$. The maximum likelihood estimate for $\Delta \rho$ of $45.5 \mathrm{~kg} \mathrm{~m}^{-3}$, shown in the figure, was calculated by fitting a Rayleigh distribution. This reflects the typical amplitude of density fluctuations observed in the high-resolution data. For $\bar{a} \gtrsim 0.6 \mathrm{~m}$ w.e. $\mathrm{a}^{-1}, \Delta \rho$ increases with $\bar{a}$ and there are $\approx 10$ years in the transition zone. This suggests that decadal rather than annual variations in $\rho_{\text {T }}^{\prime}$ are controlling $\Delta \rho$. For simplicity, we use the best fit expression

$$
\begin{aligned}
\Delta \rho_{G}= & {\left[(79 \pm 25) \mathrm{m} \text { w.e. }{ }^{-1} \mathrm{a} \mathrm{kg} \mathrm{m}^{-3}\right] \bar{a} } \\
& +\left[(32 \pm 10) \mathrm{kg} \mathrm{m}^{-3}\right] \quad r^{2}=0.36
\end{aligned}
$$

to estimate the global transition half-width, although this will slightly underestimate $\Delta \rho$ at very low-accumulation rates.

We are now able to compare the performance of the HL(T) model using global parameters with the optimised $\mathrm{HL}(\mathrm{V})$ model. Figure 14 shows the difference between predicted and observed BCO heights for the 45 available profiles. The mean difference is now $0.64 \mathrm{~m}$ for the $\mathrm{HL}(\mathrm{T})$ model using global parameters, with an r.m.s. of $3.89 \mathrm{~m}$, slightly greater than the value obtained using the local parameters but still $31 \%$ less than the value obtained using the HL model. The mean difference found using the $\mathrm{HL}(\mathrm{V})$ model is $0.84 \mathrm{~m}$, with an r.m.s. difference of $5.20 \mathrm{~m}$ (a 7\% improvement over the HL model). The HL(V) model produces a better fit than the transition model for the small ice cap profiles B38, B39 and Devon98 but a much worse fit for profiles such as South Pole and EDC2 with BCO depths $>85 \mathrm{~m}$. We should recall, however, that the $\mathrm{HL}(\mathrm{V})$ model parameters were derived using regional climate model inputs so are not necessarily the best possible set for the HL model using $T_{\mathrm{m}}$ and $\bar{a}$ as inputs.

Figure 15 shows the effect of making the thinning correction. For the 15 profiles corrected for thinning, the mean difference is $0.51 \mathrm{~m}$ for the HL(T) model with global parameters, $-1.39 \mathrm{~m}$ for the HL model and $0.82 \mathrm{~m}$ for the HL(V) model. The corresponding r.m.s. values are 2.82, 6.62 and $6.64 \mathrm{~m}$. The improvement in r.m.s. of $58 \%$ for the transition model with respect to the HL (V) model is quite marked.

It is important to remember that, since we match the observed and simulated profiles at the start of the transition region (see Section 2), the residual differences between modelled and observed nominal BCO depths are not affected by the choice of $k_{0}$. They may indicate that the expression for $k_{1}$ needs to be 


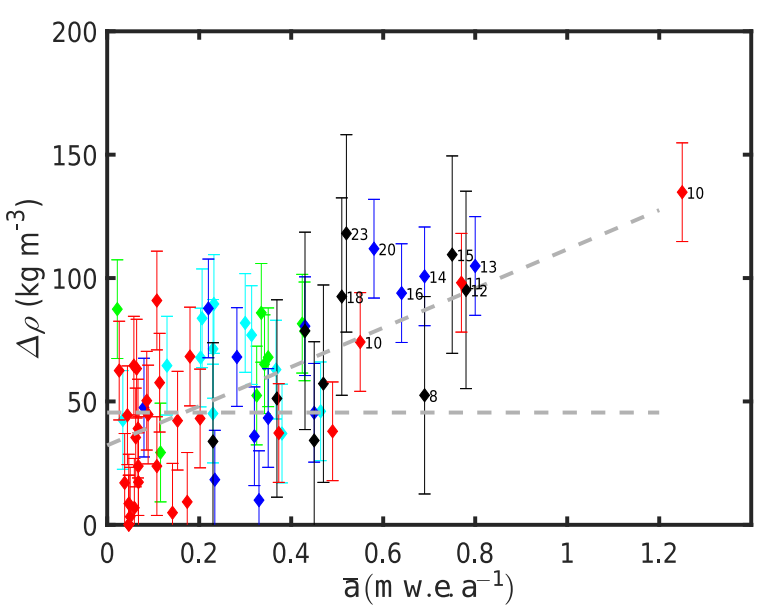

Fig. 13. Optimised values of the transition half-width, $\Delta \rho$, as a function of accumulation, $\bar{a}$. Error bars show the estimated uncertainty in individual values. The data are divided into groups according to the measurement techniques used and the quality of the density data (Section 3.3). The dashed lines show the maximum likelihood estimate for $\Delta \rho$ and the best linear fit. Labels show the estimated length of the transition zone in years.

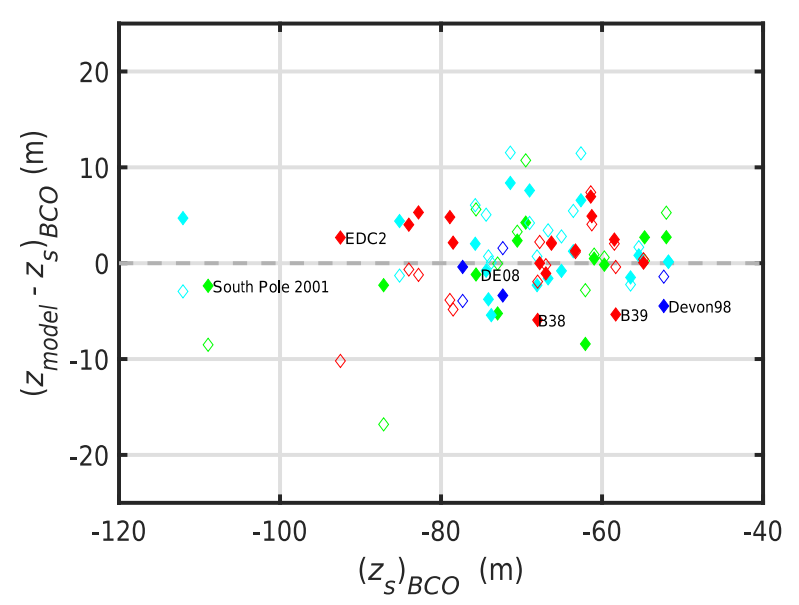

Fig. 14. Difference between predicted and observed BCO heights. Predicted heights are calculated using the $\mathrm{HL}(\mathrm{V})$ model (Verjans and others, 2020) $(\diamond)$, and the $\mathrm{HL}(\mathrm{T})$ model with global parameters $\rho_{\mathrm{TG}}$ and $\Delta \rho_{G}(\diamond)$. The points are divided into groups according to the measurement techniques used and the quality of the density data (Section 3.3).

revised, but it is also the case that such differences could arise because of temporal variations in the climate or because the transition to stage 3 densification has begun before the nominal transition density of $815 \mathrm{~kg} \mathrm{~m}^{-3}$. Incorporating a gradual transition between stages 2 and 3 would be a natural extension of the HL(T) model.

\section{Conclusion}

We have adapted the classical Herron and Langway macroscale model for dry snow densification to include a transition zone between stage 1 , in which grain-boundary sliding is the dominant process, and stage 2 , in which power-law creep is dominant. In terms of the HL densification rates $k_{0}$ and $k_{1}$, the strain rate equation becomes

$$
\begin{aligned}
\dot{\varepsilon}= & -\frac{\bar{a}}{2}\left(\frac{\rho_{\mathrm{i}}-\rho}{\rho}\right) \\
& \times\left(k_{0}+k_{1}\right)-\frac{2.06\left(k_{0}-k_{1}\right)\left(\frac{\rho-\rho_{\mathrm{T}}}{\Delta \rho}\right)}{\left|\left(1+\left(2.06\left(\frac{\rho-\rho_{\mathrm{T}}}{\Delta \rho}\right)\right)^{2}\right)^{1 / 2}\right|} \mid
\end{aligned}
$$

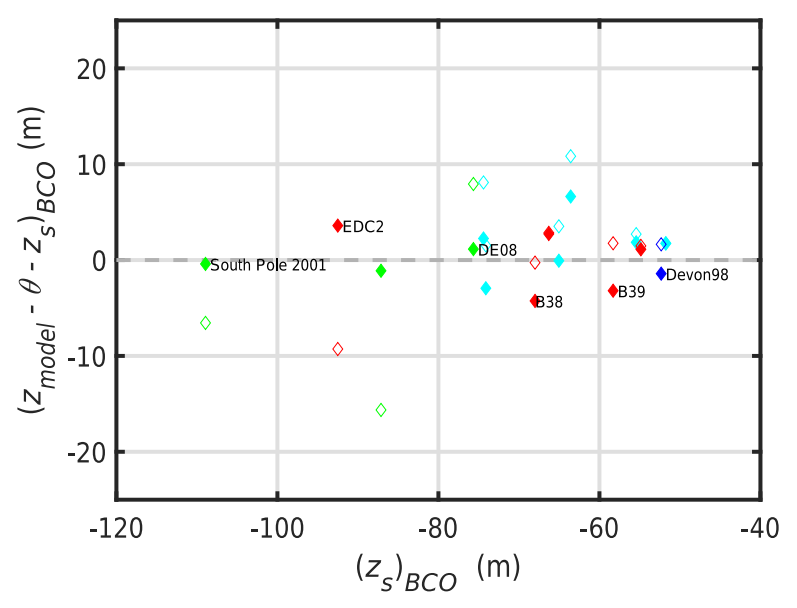

Fig. 15. Difference between predicted and observed BCO heights, corrected for thinning. Predicted heights are calculated using the $\mathrm{HL}(\mathrm{V})$ model (Verjans and others, 2020) $(\diamond)$, and the $\mathrm{HL}(\mathrm{T})$ model with global parameters $\rho_{\mathrm{TG}}$ and $\Delta \rho_{G}(\diamond)$. The points are divided into groups according to the measurement techniques used and the quality of the density data (Section 3.3).

We suggest equations for the transition parameters, $\rho_{\mathrm{T}}$ and $\Delta \rho$, based on our view of the underlying physical processes:

$$
\begin{aligned}
\rho_{\mathrm{T}}= & {\left[(359 \pm 400) \mathrm{kg} \mathrm{m}^{-3} \mathrm{~m} \text { w.e. }\right]\left(k_{0}-k_{1}\right) } \\
& +[(0.300 \pm 0.156)] \rho_{0}+\left[(404 \pm 51) \mathrm{kg} \mathrm{m}^{-3}\right]
\end{aligned}
$$

and

$$
\begin{aligned}
\Delta \rho= & {\left[(79 \pm 25) \mathrm{m} \mathrm{w.e.}^{-1} \mathrm{a} \mathrm{kg} \mathrm{m}^{-3}\right] \bar{a} } \\
& +\left[(32 \pm 10) \mathrm{kg} \mathrm{m}^{-3}\right],
\end{aligned}
$$

and show that predictions of the depth of the nominal BCO horizon, when the firn density reaches $815 \mathrm{~kg} \mathrm{~m}^{-3}$, are greatly improved by the inclusion of the transition zone. We have been limited by lack of high-resolution strain rate data which could be used to test the model directly; in order to use density profile data we have had to assume steady-state conditions with a constant accumulation rate. There is a clear need for more high-resolution field data, especially from the upper $20 \mathrm{~m}$ of the firn column, collected specifically to investigate the transition zone, rather than as a by-product of other studies. In the future, advances in methods for up-scaling from microscale snow physics to macroscale equations (e.g. Löwe and others, 2013) will no doubt lead to improved equations for the transition parameters. For the moment we are content to make the point that incorporating a smooth transition into the benchmark dry snow densification model is a simple and effective way to improve its performance.

Supplementary materials. The supplementary material for this article can be found at https://doi.org/10.1017/jog.2021.95).

Acknowledgements. We acknowledge the many field researchers who have, over the years, collected the data without which this study would not have been possible. The SUMup database is supported by the U.S. National Science Foundation grant PLR 1603407. Pine Island Glacier data were collected as part of the iSTAR project funded by the UK Natural Environment Research Council under grant [10.13039/501100000270] (NE/J005797/1 and NE/ J00569X/1). Skytrain data were collected as part of the WACSWAIN project funded by the European Research Council under Grant Agreement 742224. We thank Vincent Verjans and Yalalt Nyamgerel for interesting discussions and early sight of their data. We have been greatly helped by thoughtful reviews from Dr C Max Stevens and an anonymous reviewer and also thank our Scientific Editor, Dr Alan Rempel for his comments. 


\section{References}

Abram NJ and 8 others (2013) Acceleration of snow melt in an Antarctic Peninsula ice core during the twentieth century. Nature Geoscience 6, 404-411. doi:10.1038/ngeo1787

Alley RB and Bentley CR (1988) Ice-core analysis on the Siple Coast of West Antarctica. Annals of Glaciology 11, 1-7. doi:10.3189/S0260305500006236

Arnaud L, Lipenkov VY, Barnola JM, Gay M and Duval P (1998) Modelling of the densification of polar firn: characterization of the snow-firn transition. Annals of Glaciology 26, 39-44. doi:10.3189/1998aog26-1-39-44

Arthern RJ, Vaughan DG, Rankin AM, Mulvaney R and Thomas ER (2010) In-situ measurements of Antarctic snow compaction compared with predictions of models. Journal of Geophysical Research 115(F03011) 10.1029/ 2009JF001306.

Bader HP and Weilenmann P (1992) Modeling temperature distribution, energy and mass flow in a (phase-changing) snowpack. i. model and case studies. Cold Regions Science and Technology 20, 157-181.

Barnola JM, Pimienta P, Raynaud D and Korotkevich YS (1991) $\mathrm{CO}_{2}$-climate relationship as deduced from the Vostok ice core - a re-examination based on new measurements and on a re-evaluation of the air dating. Tellus B 43(2), 83-90. doi:10.1034/j.1600-0889.1991.t01-100002.x

Benson CS (1962) Stratigraphic studies in the snow and firn of the Greenland Ice Sheet. SIPRE Research Report 70, 93. doi:10.21236/ada337542

Breton DJ, Hamiliton GS and Hess CT (2009) Instruments and methods design, optimization and calibration of an automated density gauge for firn and ice cores. Journal of Glaciology 55(194), 1092-1100. doi:10.3189/ 002214309790794841

Brun E, Martin E, Simon V, Gendre C and Coleov C (1989) An energy and mass model of snow cover suitable for operational avalanche forecasting. Journal of Glaciology 35(121), 333-342. (doi:10.3189/S0022143000009254)

Ebinuma T and Maeno N (1987) Particle rearrangement and dislocation creep in a snow-densification process. Journal de Physique Colloque 3(48 Suppl.), 263-269. doi:10.1051/jphyscol:1987137

Fourteau K, Gillet-Chaulet F, Martinerie P and Fan X (2020) A micromechanical model for the transformation of dry polar firn into ice using the level-set method. Frontiers in Earth Science 8(101). doi:10.3389/feart. 2020.00101).

Freitag J, Wilhelms F and Kipfstuhl S (2004) Microstructure-dependent densification of polar firn derived from x-ray microtomography. Journal of Glaciology 50(169), 243-250. doi:10.3189/172756504781830123

Gerland S and 5 others (1999) Density log of a $181 \mathrm{~m}$ long ice core from Berkner Island, Antarctica. Annals of Glaciology 29, 215-219. doi:10. 3189/172756499781821427

Goujon C, Barnola JM and Ritz C (2003) Modeling the densification of polar firn including heat diffusion: application to close-off characteristics and gas isotopic fractionation for Antarctica and Greenland sites. Journal of Geophysical Research 108(D24)doi:10.1029/2002JD003319.

Hawley RL and Morris EM (2006) Borehole optical stratigraphy and neutronscattering density measurements at Summit, Greenland. Journal of Glaciology 52(179), 491-496. doi:10.3189/172756506781828368

Hawley RL, Morris EM and McConnell JR (2008) Rapid techniques for determining annual accumulation applied at Summit, Greenland. Journal of Glaciology 54(188), 839-845. doi:10.3189/002214308787779951

Herron MM and Langway CC (1980) Firn densification: an empirical model. Journal of Glaciology 25(93), 373-385. doi:10.3189/S002214300001523

Hörhold MW, Kipfstuhl S, Wilhelms F, Freitag J and Frenzel A (2011) The densification of layered polar firn. Journal of Geophysical Research: Earth Surface 116(F1), 1-15. doi:10.1029/2009jf001630

Hörhold MW and 5 others (2012) On the impact of impurities on the densification of polar firn. Earth and Planetary Science Letters 325-326, 93-99. doi:10.1016/j.epsl.2011.12.022

Horlings AN, Christianson K, Holschuh ND, Stevens CM and Waddington ED (2020) Effect of horizontal divergence on estimates of firn-air content. Journal of Glaciology 67(262), 287-296. doi:10.1017/jog.2020.105

Jordan R (1991) A one-dimensional temperature model for a snow cover. Technical documentation for SNTHERM.89. Cold Regions Research and Engineering Laboratory Special Report, 657.

Kameda T, Shoji H, Kawada K, Watanabe O and Clausen HB (1994) An empirical relation between overburden pressure and firn density. Annals of Glaciology 20, 87-94. doi:10.3189/1994aog20-1-87-94
Koerner RM (1977) Devon Island Ice Cap: Core stratigraphy and paleoclimate. Science (New York, N.Y.) 196(4285), 15-18. doi:10.1126/science. 196.4285.15

Ligtenberg SRM, Helsen MM and van den Broeke MR (2011) An improved semi-empirical model for the densification of Antarctic firn. The Cryosphere 5(4), 809-819. doi:10.5194/tc-5-809-2011

Löwe H, Riche F and Schneebeli M (2013) A general treatment of snow microstructure exemplified by an improved relation for the thermal conductivity. The Cryosphere 7, 1743. doi:10.5194/tc-7-1473-2013

Lundin $J$ and 12 others (2017) Firn model intercomparison experiment (FirnMICE). Journal of Glaciology 63(239), 401-422. (doi:10.1017/jog. 2016.114)

Martinerie P and 5 others (1994) Air content paleo record in the Vostok ice core (Antarctica): a mixed record of climatic and glaciological parameters. Journal of Geophysical Research 99(D5), 10565-10576. doi:10.1029/ 93JD03223

Montgomery LN, Koenig L and Alexander P (2018) The SUMup dataset: compiled measurements of surface mass balance components over ice sheets and sea ice with preliminary analysis over Greenland. Earth System Science Data 10(4), 1959-1985. doi:10.5194/essd-10-1959-2018

Morris EM and 9 others (2017) Snow densification and recent accumulation along the iSTAR Traverse, Pine Island Glacier, Antarctica. Journal of Geophysical Research: Earth Surface 122, 2284-2301. doi:10.1002/ 2017jf004357

Morris EM (2018) Modelling dry-snow densification without abrupt transition. Geosciences 8(12), 464. doi:10.3390/geosciences8120464

Morris EM and Cooper JD (2003) Density measurements in ice boreholes using neutron scattering. Journal of Glaciology 49(167), 599-604. doi:10. 3189/17275650378183040

Morris EM and Wingham DJ (2014) Densification of polar snow: measurements, modelling and implications for altimetry. JGR Earth Surfaces 119. doi:10.1002/2013JF002898

Nye JF (1963) Correction factor for accumulation measured by the thickness of annual layers in an ice sheet. Journal of Glaciology 4(36), 785-788. doi:10. 3189/S0022143000028367

Parrenin F and 15 others (2007) 1-D-ice flow modelling at EPICA Dome C and Dome Fuji, East Antarctica. Climate of the Past 3(2), 243-259. doi:10. 5194/cp-3-243-2007

Paterson WSB and Waddington E (1984) Past precipitation rates derived from ice core measurements: methods and data analysis. Reviews of Geophysics and Space Physics 22(2), 123-130. doi:10.1029/rg022i002p00123

Raymond C and 5 others (1996) Geometry, motion and mass balance of Dyer Plateau, Antarctica. Journal of Glaciology 42, 510-518. doi:10.3189/ s002214300000349x

Reeh N, Fisher DA, Koerner RM and Clausen HB (2005) An empirical firndensification model comprising ice lenses. Annals of Glaciology 42, 101106. doi:10.3189/172756405781812871

Riverman K and 7 others (2017) Enhanced firn densification in high accumulation shear margins of the NE Greenland Ice Stream. Journal of Geophysical Research Earth Surface 124, 365-382. doi:10.1029/ 2017JF004604

Salamatin AN and Lipenkov VY (2008) Simple relations for the close-off depth and age in dry-snow densification. Annals of Glaciology 49, 71-76. doi:10.3189/172756408787814889

Salamatin AN and 5 others (2009) Snow/firn densification in polar ice sheets. In T Hondoh (ed.), Physics of Ice Core Records II, volume 68 of Low Temperature Science, 195-222, ILTS, Hokkaido University, Sapporo.

Schmidt KM and 5 others (2014) Calcium, dust and nitrate concentrations in monthly resolution in ice core DML94C07_38 (B38). PANGAEA 4. doi:10. 1594/PANGAEA.837875

Simonsen SB and 5 others (2013) Assessing a multilayered dynamic firncompaction model for Greenland with ASIRAS radar measurements. Journal of Glaciology 59(215), 545-558. doi:10.3189/2013jog12j158

Spencer M, Alley RB and Creyts T (2001) Preliminary firn-densification model with 38-site dataset. Journal of Glaciology 47(159), 671-676. doi: $10.3189 / 172756501781831765$

Verjans V and 6 others (2020) Bayesian calibration of firn densification models. The Cryosphere 13, 3023-3043. doi:10.5194/tc-2019-274

Wilhelms F (1996) Leitfähigkeits- und Dichtemessungen an Eisbohrkernen (Measuring the conductivity and density of ice cores). Berichte zur Polarforschung 191, 224. 
Appendix A. Density profile data

Table A1. Optimised values for gamma-ray attenuation density profiles

\begin{tabular}{|c|c|c|c|c|c|c|c|c|c|c|}
\hline Core & $\begin{array}{c}\bar{a} \\
\text { m w.e. } a^{-1}\end{array}$ & $\begin{array}{l}T_{\mathrm{m}} \\
{ }^{\circ} \mathrm{C}\end{array}$ & $\begin{array}{c}\rho_{\mathrm{T}} \\
\mathrm{kg} \mathrm{m}^{-3}\end{array}$ & $\begin{array}{c}\Delta \rho \\
\mathrm{kg} \mathrm{m}^{-3}\end{array}$ & $\begin{array}{c}\rho_{0} \\
\mathrm{~kg} \mathrm{~m}^{-3}\end{array}$ & $\begin{array}{l}z_{\mathrm{T}} \\
\mathrm{m}\end{array}$ & $\begin{array}{c}q_{\mathrm{T}} \\
\mathrm{m} \text { w.e. }\end{array}$ & $\begin{array}{c}\Delta z_{\mathrm{BCO}} \\
\mathrm{m}\end{array}$ & $\begin{array}{c}\Delta D I P \\
\mathrm{~m}\end{array}$ & $\begin{array}{l}\Psi_{\min } \\
10^{-4}\end{array}$ \\
\hline $\mathrm{EDC}^{\star}{ }^{\star}$ & 0.0261 & -54.65 & 514 & 63 & 353 & -19.489 & 8.465 & -1.550 & 0.720 & 38 \\
\hline BER11C95_25(B25)* & 0.174 & -27.0 & 532 & 9 & 390 & -8.960 & 4.138 & -0.930 & 0.383 & 224 \\
\hline DML95* & 0.550 & -19.2 & 550 & 74 & 444 & -6.334 & 3.152 & 3.425 & -1.120 & 451 \\
\hline DML97* & 0.490 & -20.4 & 557 & 38 & 425 & -7.886 & 3.840 & 2.402 & -0.859 & 390 \\
\hline NM03C98_01* & 0.373 & -17.0 & 534 & 37 & 416 & -6.324 & 3.013 & -0.278 & 0.154 & 863 \\
\hline DML18C98_04 & 0.050 & -40.5 & 543 & 3 & 370 & -14.808 & 6.739 & -0.251 & 0.102 & 99 \\
\hline DML19C98_05 & 0.044 & -43.4 & 515 & 44 & 367 & -13.514 & 5.971 & -1.126 & 0.497 & 131 \\
\hline DML20C98_08 & 0.0676 & -43.1 & 517 & 24 & 368 & -13.440 & 5.958 & -1.927 & 0.819 & 219 \\
\hline DML03C98_09* & 0.089 & -42.2 & 507 & 45 & 394 & -10.213 & 4.618 & -2.674 & 1.185 & 157 \\
\hline DML21C98_10* & 0.086 & -44.0 & 517 & 50 & 389 & -12.143 & 5.520 & -1.790 & 0.828 & 60 \\
\hline DML2298_11* & 0.058 & -46.1 & 520 & 65 & 380 & -13.971 & 6.309 & -1.106 & 0.555 & 201 \\
\hline DML23C98_12* & 0.038 & -45.8 & 524 & 17 & 365 & -15.306 & 6.792 & -0.972 & 0.407 & 38 \\
\hline DML16C98_13* & 0.047 & -42.3 & 513 & 0 & 357 & -13.655 & 5.937 & -0.0002 & 0.617 & 91 \\
\hline DML15C98_14* & 0.064 & -45.0 & 525 & 63 & 367 & -15.223 & 6.814 & -0.767 & 0.414 & 121 \\
\hline DML13C98_16* & 0.047 & -42.3 & 535 & 9 & 371 & -14.645 & 6.390 & -0.538 & 0.221 & 121 \\
\hline DML12C98_17 & 0.068 & -40.2 & 540 & 17 & 376 & -13.770 & 6.320 & -0.348 & 0.149 & 127 \\
\hline DML07C98_31(B31)* & 0.059 & -44.3 & 527 & 7 & 357 & -15.605 & 6.904 & -1.409 & 0.582 & 275 \\
\hline DML05C98_32(B32) & 0.062 & -44.5 & 511 & 35 & 366 & -13.564 & 5.923 & -2.231 & 0.968 & 275 \\
\hline DML17C98_33(B33) & 0.047 & -46.1 & 514 & 0 & 371 & -13.645 & 6.040 & -2.058 & 0.863 & 345 \\
\hline B36/B37(EDML) & 0.067 & -44.6 & 509 & 39 & 369 & -13.302 & 5.598 & -2.471 & 1.082 & 124 \\
\hline DML94C07_38(B38)* & 1.250 & -18.1 & 549 & 135 & 432 & -7.264 & 3.523 & 13.689 & -4.201 & 93 \\
\hline DML96C07_39(B39)* & 0.770 & -17.9 & 552 & 98 & 437 & -6.880 & 3.395 & 6.375 & -2.042 & 1784 \\
\hline ngt03c93_2(B16) ${ }^{\star}$ & 0.142 & -27.0 & 509 & 5 & 342 & -10.444 & 4.428 & -1.185 & 0.796 & 116 \\
\hline ngt06C93_2(B17)* & 0.114 & -32.3 & 519 & 58 & 335 & -13.421 & 5.744 & -0.968 & 0.462 & 110 \\
\hline ngt14c93_2(B18) & 0.108 & -30.0 & 524 & 91 & 330 & -13.579 & 5.810 & -0.355 & 0.245 & 84 \\
\hline ngt27c94_2(B21)* & 0.108 & -30.0 & 509 & 24 & 326 & -12.529 & 5.229 & -1.542 & 0.659 & 168 \\
\hline ngt37C95_2(B26) ${ }^{\star}$ & 0.180 & -30.6 & 513 & 68 & 350 & -11.812 & 5.099 & -1.263 & 0.641 & 81 \\
\hline ngt42c95_2(B29)* & 0.153 & -31.6 & 532 & 42 & 328 & -14.515 & 6.252 & -0.480 & 0.247 & 8 \\
\hline WDC06A(WAIS Divide)* & 0.202 & -31.0 & 542 & 43 & 428 & -8.2052 & 3.996 & 0.587 & -0.163 & 199 \\
\hline
\end{tabular}

${ }^{*}$ Profile used to determine global equations for $\rho_{\text {TG. }}$.

Table A2. Optimised values for neutron scattering density profiles

\begin{tabular}{|c|c|c|c|c|c|c|c|c|c|c|}
\hline Site & $\begin{array}{c}\bar{a} \\
\text { m w.e. } a^{-1}\end{array}$ & $\begin{array}{l}T_{\mathrm{m}} \\
{ }^{\circ} \mathrm{C}\end{array}$ & $\begin{array}{c}\rho_{\mathrm{T}} \\
\mathrm{kg} \mathrm{m}^{-3}\end{array}$ & $\begin{array}{c}\Delta \rho \\
\mathrm{kg} \mathrm{m}^{-3}\end{array}$ & $\begin{array}{c}\rho_{0} \\
\mathrm{~kg} \mathrm{~m}^{-3}\end{array}$ & $\begin{array}{l}z_{\mathrm{T}} \\
\mathrm{m}\end{array}$ & $\begin{array}{c}q_{\mathrm{T}} \\
\text { m w.e. }\end{array}$ & $\begin{array}{c}\Delta z_{\mathrm{BCO}} \\
\mathrm{m}\end{array}$ & $\begin{array}{c}\Delta D I P \\
\mathrm{~m}\end{array}$ & $\begin{array}{l}\Psi_{\min } \\
10^{-4}\end{array}$ \\
\hline Katie* & 0.216 & -31 & 532. & 20 & 352 & -12.547 & 5.556 & -1.046 & 0.445 & 155 \\
\hline iSTAR01* & 0.35 & -25.5 & 566 & 50 & 436 & -8.399 & 4.223 & 3.760 & -1.330 & 836 \\
\hline iSTAR03* & 0.43 & -24.3 & 567 & 79 & 451 & -7.770 & 3.962 & 5.868 & -1.970 & 377 \\
\hline iSTAR04 & 0.58 & -23.6 & 571 & 106 & 446 & -8.294 & 4.202 & 9.927 & -3.213 & 431 \\
\hline iSTAR05* & 0.45 & -23.1 & 570 & 34 & 443 & -7.776 & 3.949 & 3.898 & -1.423 & 560 \\
\hline iSTAR06 & 0.45 & -22.6 & 559 & 83 & 438 & -7.721 & 3.853 & 4.816 & -1.592 & 219 \\
\hline iSTAR07 & 0.33 & -22.6 & 574 & 84 & 425 & -9.330 & 4.676 & 2.715 & -1.013 & 217 \\
\hline iSTAR08 & 0.32 & -22.2 & 566 & 41 & 420 & -8.742 & 4.328 & 2.497 & -0.901 & 138 \\
\hline iSTAR09* & 0.369 & -22.2 & 562 & 51 & 428 & -8.138 & 4.042 & 2.902 & -1.019 & 256 \\
\hline iSTAR10* & 0.234 & -21.5 & 553 & 37 & 424 & -7.508 & 3.683 & 0.754 & -0.266 & 225 \\
\hline iSTAR11 & 0.23 & -21.9 & 562 & 34 & 428 & -7.824 & 3.886 & 1.228 & -0.449 & 181 \\
\hline iSTAR13* & 0.43 & -22.4 & 563 & 56 & 433 & -7.991 & 3.908 & 3.765 & -1.313 & 336 \\
\hline iSTAR14 & 0.47 & -22.4 & 568 & 57 & 435 & -8.180 & 4.114 & 4.792 & -1.671 & 877 \\
\hline iSTAR15* & 0.80 & -21.9 & 554 & 109 & 446 & -7.064 & 3.513 & 9.699 & -3.088 & 534 \\
\hline iSTAR16 & 0.51 & -21.9 & 564 & 93 & 429 & -8.464 & 4.200 & 6.278 & -2.058 & 205 \\
\hline iSTAR17 & 0.52 & -21.2 & 581 & 118 & 442 & -8.797 & 4.493 & 9.433 & -3.018 & 72 \\
\hline iSTAR18 & 0.69 & -19.58 & 554 & 125 & 435 & -7.460 & 3.674 & 8.029 & -2.505 & 305 \\
\hline iSTAR19 & 0.69 & -20.16 & 579 & 53 & 447 & -7.831 & 4.022 & 7.396 & -2.590 & 261 \\
\hline iSTAR20 & 0.64 & -22.76 & 560 & 96 & 443 & -7.650 & 3.824 & 8.211 & -2.669 & 544 \\
\hline iSTAR21 & 0.75 & -22.31 & 566 & 110 & 444 & -7.975 & 3.999 & 11.288 & -3.626 & 484 \\
\hline iSTAR22 & 0.78 & -20.12 & 564 & 95 & 440 & -7.604 & 3.803 & 8.965 & -2.927 & 663 \\
\hline
\end{tabular}

${ }^{*}$ Profile used to determine global equations for $\rho_{\text {TG }}$. 
Table A3. Optimised values for group A gravimetric density profiles

\begin{tabular}{|c|c|c|c|c|c|c|c|c|c|c|}
\hline Core & $\begin{array}{c}\bar{a} \\
\text { m w.e. } a^{-1}\end{array}$ & $\begin{array}{l}T_{\mathrm{m}} \\
{ }^{\circ} \mathrm{C}\end{array}$ & $\begin{array}{c}\rho_{\mathrm{T}} \\
\mathrm{kg} \mathrm{m}^{-3}\end{array}$ & $\begin{array}{c}\Delta \rho \\
\mathrm{kg} \mathrm{m}^{-3}\end{array}$ & $\begin{array}{c}\rho_{0} \\
\mathrm{~kg} \mathrm{~m}^{-3}\end{array}$ & $\begin{array}{l}z_{T} \\
m\end{array}$ & $\begin{array}{c}q_{\mathrm{T}} \\
\text { m w.e. }\end{array}$ & $\begin{array}{c}\Delta z_{\mathrm{BCO}} \\
\mathrm{m}\end{array}$ & $\begin{array}{c}\Delta D I P \\
\mathrm{~m}\end{array}$ & $\begin{array}{l}\Psi_{\min } \\
10^{-4}\end{array}$ \\
\hline iSTAR01 & 0.35 & -25.3 & 568 & 43 & 437 & -8.437 & 4.255 & 3.719 & -1.335 & 665 \\
\hline iSTAR04 & 0.58 & -23.3 & 561 & 112 & 440 & -8.062 & 4.022 & 8.861 & -2.828 & 580 \\
\hline iSTAR06 & 0.45 & -22.6 & 573 & 35 & 438 & -8.154 & 4.136 & 3.357 & -1.193 & 281 \\
\hline iSTAR07 & 0.33 & -22.6 & 574 & 10 & 420 & -9.012 & 4.495 & 2.383 & -0.912 & 1153 \\
\hline iSTAR08 & 0.32 & -22.2 & 570 & 36 & 424 & -8.660 & 4.323 & 2.654 & -0.969 & 398 \\
\hline iSTAR10 & 0.234 & -21.5 & 561 & 18 & 418 & -8.222 & 4.035 & 0.908 & -0.346 & 391 \\
\hline iSTAR13 & 0.43 & -22.4 & 558 & 81 & 439 & -7.464 & 3.730 & 4.224 & -1.395 & 867 \\
\hline iSTAR15 & 0.8 & -21.9 & 551 & 105 & 453 & -6.509 & 3.252 & 9.012 & -2.870 & 436 \\
\hline iSTAR18 & 0.69 & -19.58 & 554 & 101 & 437 & -7.185 & 3.553 & 6.690 & -2.143 & 568 \\
\hline iSTAR20 & 0.64 & -22.76 & 568 & 94 & 442 & -8.186 & 4.124 & 9.321 & -3.058 & 221 \\
\hline Devon98 & 0.22 & -23.3 & 510 & 88 & 332 & -11.051 & 4.667 & -0.962 & 0.534 & 203 \\
\hline Site A & 0.282 & -29.41 & 525 & 7 & 359 & -11.653 & 5.170 & 0.130 & 0.127 & 206 \\
\hline Mizuho G6 & 0.08 & -43.0 & 522 & 48 & 388 & -12.329 & 5.629 & -1.289 & 0.599 & 283 \\
\hline Dyer88* & 0.552 & -21.36 & 544 & 17 & 418 & -7.261 & 3.501 & 0.211 & -0.062 & 732 \\
\hline
\end{tabular}

*Less than 10 measurements in transition zone.

Table A4. Optimised values for group B gravimetric density profiles

\begin{tabular}{|c|c|c|c|c|c|c|c|c|c|c|}
\hline Core & $\begin{array}{c}\bar{a} \\
\text { m w.e. } a^{-1}\end{array}$ & $\begin{array}{l}T_{\mathrm{m}} \\
{ }^{\circ} \mathrm{C}\end{array}$ & $\begin{array}{c}\rho_{\mathrm{T}} \\
\mathrm{kg} \mathrm{m}^{-3}\end{array}$ & $\begin{array}{c}\Delta \rho \\
\mathrm{kg} \mathrm{m}^{-3}\end{array}$ & $\begin{array}{c}\rho_{0} \\
\mathrm{~kg} \mathrm{~m}^{-3}\end{array}$ & $\begin{array}{l}z_{\mathrm{T}} \\
\mathrm{m}\end{array}$ & $\begin{array}{c}q_{\mathrm{T}} \\
\text { m w.e. }\end{array}$ & $\begin{array}{c}\Delta z_{\mathrm{BCO}} \\
\mathrm{m}\end{array}$ & $\begin{array}{c}\Delta D I P \\
\mathrm{~m}\end{array}$ & $\begin{array}{l}\Psi_{\min } \\
10^{-4}\end{array}$ \\
\hline Eismitte & 0.314 & -28.3 & 512 & 77 & 381 & -9.129 & 4.093 & -0.856 & 0.570 & 106 \\
\hline Camp Century & 0.367 & -24.35 & 547 & 63 & 366 & -11.387 & 5.220 & 2.237 & -0.722 & 100 \\
\hline StyxA & 0.13 & -31.7 & 530 & 65 & 398 & -9.541 & 4.443 & -0.242 & 0.182 & 135 \\
\hline Katie & 0.23 & -31 & 539 & 45 & 367 & -12.190 & 5.543 & 0.527 & -0.123 & 124 \\
\hline Dome GRIP & 0.232 & -31.65 & 527 & 90 & 347 & -13.336 & 5.852 & 0.972 & -0.122 & 218 \\
\hline NEEM 2009S2 & 0.203 & -28.15 & 499 & 68 & 334 & -11.265 & 4.703 & -2.304 & 1.083 & 165 \\
\hline DIV2010* & 0.41 & -24 & 549 & 16 & 444 & -6.394 & 3.182 & 0.610 & -0.225 & 444 \\
\hline THW2010* & 0.28 & -28 & 521 & 11 & 415 & -6.857 & 3.217 & -2.443 & 1.019 & 483 \\
\hline ITASE02_6* & 0.074 & -50.45 & 519 & 5 & 377 & -15.102 & 6.765 & -4.028 & 1.680 & 469 \\
\hline Dome C & 0.034 & -53.5 & 518 & 43 & 357 & -18.866 & 8.278 & -1.767 & 0.783 & 37 \\
\hline Site A (US)* & 0.2659 & -29.5 & 521 & 3 & 364 & -10.688 & 4.747 & -1.781 & 0.778 & 174 \\
\hline Site B & 0.3 & -29.48 & 530 & 82 & 345 & -13.146 & 5.771 & 1.448 & -0.314 & 60 \\
\hline Site $\mathrm{E}$ & 0.2063 & -30.37 & 529 & 84 & 351 & -12.720 & 5.623 & 0.569 & -0.038 & 94 \\
\hline Site G & 0.2302 & -30.10 & 522 & 71 & 353 & -12.137 & 5.323 & -0.268 & 0.272 & 61 \\
\hline James Ross I.* & 0.63 & -14.4 & 552 & 4 & 393 & -7.924 & 3.703 & 0.333 & -0.131 & 589 \\
\hline Fletcher Prom. & 0.38 & -27.1 & 531 & 37 & 394 & -9.016 & 4.183 & -0.372 & 0.231 & 225 \\
\hline Skytrain Ice Rise* & 0.18 & -25.9 & 532 & 1 & 411 & -7.447 & 3.520 & -1.091 & 0.418 & 200 \\
\hline $\mathrm{T} 1$ (Berkner) $^{\star}$ & 0.174 & -26.5 & 544 & 1 & 382 & -10.088 & 4.649 & -0.521 & 0.211 & 349 \\
\hline Beethoven Pen. ${ }^{\star}$ & 1.06 & -12.13 & 554 & 8 & 399 & -7.446 & 3.555 & 1.038 & -0.403 & 516 \\
\hline BAS $M 1^{\star}$ & 0.071 & -28.3 & 493 & 7 & 364 & -10.149 & 4.351 & -2.610 & 1.125 & 374 \\
\hline BAS ISOL* & 0.067 & -44.6 & 507 & 28 & 362 & -13.636 & 5.935 & -2.827 & 1.215 & 153 \\
\hline Dyer89 & 0.464 & -21.36 & 520 & 46 & 415 & -6.247 & 2.929 & -1.155 & 0.567 & 318 \\
\hline
\end{tabular}

*Less than 10 measurements in transition zone.

Table A5. Optimised values for group C gravimetric density profiles

\begin{tabular}{|c|c|c|c|c|c|c|c|c|c|c|}
\hline Core & $\begin{array}{c}\bar{a} \\
\text { m w.e. } a^{-1}\end{array}$ & $\begin{array}{l}T_{\mathrm{m}} \\
{ }^{\circ} \mathrm{C}\end{array}$ & $\begin{array}{c}\rho_{\mathrm{T}} \\
\mathrm{kg} \mathrm{m}^{-3}\end{array}$ & $\begin{array}{c}\Delta \rho \\
\mathrm{kg} \mathrm{m}^{-3}\end{array}$ & $\begin{array}{c}\rho_{0} \\
\mathrm{~kg} \mathrm{~m}^{-3}\end{array}$ & $\begin{array}{l}z_{\mathrm{T}} \\
\mathrm{m}\end{array}$ & $\begin{array}{c}q_{\mathrm{T}} \\
\text { m w.e. }\end{array}$ & $\begin{array}{c}\Delta z_{\mathrm{BCO}} \\
\mathrm{m}\end{array}$ & $\begin{array}{c}\Delta D I P \\
\mathrm{~m}\end{array}$ & $\begin{array}{l}\Psi_{\min } \\
10^{-4}\end{array}$ \\
\hline Vostok (BH-3 BH-5) & 0.022 & -55.5 & 518 & 87 & 340 & -22.154 & 9.526 & -0.971 & 0.508 & 34 \\
\hline Inge Lehmann* & 0.1 & -32.5 & 509 & 63 & 421 & -6.509 & 3.032 & -1.340 & 0.619 & 115 \\
\hline PIG2010 & 0.424 & -30.4 & 549 & 82 & 428 & -9.685 & 4.686 & 6.012 & -1.944 & 345 \\
\hline ITASE00_1(WAIS)* & 0.218 & -31.1 & 541 & 44 & 410 & -9.337 & 4.459 & 0.675 & -0.184 & 241 \\
\hline ITASE01_2 & 0.429 & -27.83 & 559 & 78 & 420 & -9.282 & 4.579 & 6.287 & -2.082 & 225 \\
\hline ITASE01_3 & 0.35 & -30.4 & 547 & 68 & 416 & -9.507 & 4.678 & 3.625 & -1.175 & 366 \\
\hline ITASE01_4 & 0.325 & -30.15 & 554 & 52 & 420 & -7.736 & 3.032 & 3.309 & -1.135 & 262 \\
\hline ITASE01_5 & 0.342 & -27.0 & 549 & 65 & 354 & -8.774 & 4.262 & 2.851 & -0.932 & 154 \\
\hline ITASE02_4* & 0.16 & -40.12 & 532 & 29 & 396 & -11.572 & 5.386 & -0.988 & 0.456 & 284 \\
\hline ITASE02_1* & 0.19 & -29.48 & 571 & 14 & 411 & -10.773 & 5.289 & 1.984 & -0.758 & 240 \\
\hline Byrd $^{*}$ & 0.214 & -28 & 548 & 31 & 393 & -10.248 & 4.840 & 0.244 & -0.078 & 242 \\
\hline DE08 DE08-2* & 1.1 & -19 & 553 & 24 & 406 & -8.158 & 3.919 & 2.909 & -1.068 & 949 \\
\hline Dye3-4B-1983* & 0.495 & -20.1 & 540 & 24 & 366 & -9.766 & 4.433 & -0.026 & 0.045 & 251 \\
\hline Mizuho G15 & 0.116 & -37.5 & 505 & 29 & 399 & -8.502 & 3.850 & -3.022 & 1.304 & 544 \\
\hline Mizuho $\mathrm{H} 15^{\star}$ & 0.32 & -19.4 & 524 & 30 & 431 & -5.227 & 2.500 & -1.148 & 0.499 & 267 \\
\hline Site D & 0.335 & -28.3 & 533 & 86 & 351 & -12.600 & 5.586 & 2.054 & -0.531 & 64 \\
\hline South Pole $2001^{\star}$ & 0.074 & -50.45 & 519 & 23 & 350 & -18.242 & 7.939 & -3.227 & 1.371 & 174 \\
\hline
\end{tabular}

*Less than 10 measurements in transition zone. 